Published in final edited form as:

Neuroimage. 2012 September ; 62(3): 2110-2128. doi:10.1016/j.neuroimage.2012.05.079.

\title{
States of mind: Emotions, body feelings, and thoughts share distributed neural networks
}

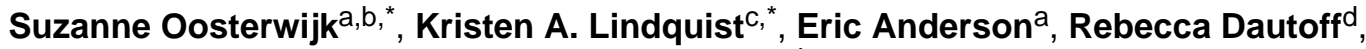 \\ Yoshiya Moriguchi ${ }^{\mathrm{e}}$, and Lisa Feldman Barrett ${ }^{\mathrm{a}, \mathrm{d}}$
}

aNortheastern University, Nightingale Hall, Boston, MA Boston, MA 02115-5000 USA bUniversity of Amsterdam, Psychology Department, Weesperplein 4, 1018 XA Amsterdam, The Netherlands 'University of North Carolina Chapel Hill, Davie Hall, Chapel Hill, NC 27599 dMassachusetts General Hospital/Harvard Medical School/Martinos Center for Biomedical Imaging, 149 13th St. Charlestown, MA 02129 USA eNational Center of Neurology and Psychiatry, Japan, Department of Psychophysiology, National Institute of Mental Health Multimodal Neuroimaging Section, Integrative Brain Imaging, 4-1-1, Ogawa-higashi, Kodaira, Tokyo, 187-8551, Japan

\begin{abstract}
Scientists have traditionally assumed that different kinds of mental states (e.g., fear, disgust, love, memory, planning, concentration, etc.) correspond to different psychological faculties that have domain-specific correlates in the brain. Yet, growing evidence points to the constructionist hypothesis that mental states emerge from the combination of domain-general psychological processes that map to large-scale distributed brain networks. In this paper, we report a novel study testing a constructionist model of the mind in which participants generated three kinds of mental states (emotions, body feelings, or thoughts) while we measured activity within large-scale distributed brain networks using fMRI. We examined the similarity and differences in the pattern of network activity across these three classes of mental states. Consistent with a constructionist hypothesis, a combination of large-scale distributed networks contributed to emotions, thoughts, and body feelings, although these mental states differed in the relative contribution of those networks. Implications for a constructionist functional architecture of diverse mental states are discussed.
\end{abstract}

\section{Keywords}

constructionist; emotion; thought; body feelings; intrinsic networks

\section{Introduction}

During every waking moment of life, a human mind consists of a variety of mental states. These mental states are typically named in commonsense terms, such as emotions (e.g., fear,

(C) 2012 Elsevier Inc. All rights reserved.

Address correspondence to: Suzanne Oosterwijk at s.oosterwijk@neu.edu Northeastern University Department of Psychology 114 Lake Hall, Boston, MA 02115 Phone: (617) 373-3076 Fax: (617) 373-8714 .

authors contributed equally

Publisher's Disclaimer: This is a PDF file of an unedited manuscript that has been accepted for publication. As a service to our customers we are providing this early version of the manuscript. The manuscript will undergo copyediting, typesetting, and review of the resulting proof before it is published in its final citable form. Please note that during the production process errors may be discovered which could affect the content, and all legal disclaimers that apply to the journal pertain. 
disgust, love), cognitions (e.g., retrieving a memory, planning the future, concentrating on a task), perceptions (e.g., face perception, color perception, sound perception), and so on. Since the beginning of psychological science, researchers have assumed that each of these words refers to a separate and distinct kind of mental category or "faculty" (Lindquist \& Barrett, under review; Uttal, 2001). Accordingly, scientists have searched for the physical correlates of these mental categories for over a century-in behavior, in peripheral physiology, and most recently, in a functioning brain. For example, cognitive neuroscientists have attempted to identify the unified neural basis of fear (e.g., Whalen et al., 1998), disgust (e.g., Wicker et al., 2003), love (e.g., Bartels \& Zeki, 2000), the self (e.g., Northoff \& Bermpohl, 2004), episodic memory (Rugg, Otten, \& Henson, 2002), semantic memory (e.g., Grossman et al., 2002), working memory (e.g., D'Esposito et al., 1998), face perception (e.g., Kanwisher, McDermott, \& Chun, 1997) and so on. Twenty years of neuroimaging research is revealing, however, that the brain does not respect faculty psychology categories (Barrett, 2009b; Duncan \& Barrett, 2007; Gonsalves \& Cohen, 2010; Lindquist \& Barrett, under review; Lindquist, Wager, Kober, Bliss, \& Barrett, in press; Pessoa, 2008; Poldrack, 2010; Uttal, 2001).

Instead of revealing domain-specific brain areas that are specific to each mental faculty, growing evidence points to the hypothesis that diverse mental states emerge from the combination of domain-general psychological processes or "ingredients" that map to largescale distributed networks in association regions of the brain (cf., Barrett, 2009b; Barrett, 2011). In psychology, there is a theoretical tradition for hypothesizing that mental states emerge from the combination of more basic, domain-general, psychological processes-it is known as a constructionist approach. Throughout the past century, the constructionist approach has been most popular in models of emotion (e.g., Barrett, 2006, in press; Harlow \& Stagner, 1932; Lindquist, Wager, Kober, et al., in press; Russell, 2003; Schachter \& Singer, 1962; for a review see, Gendron \& Barrett, 2009), although its roots can be found in the earliest psychological writing (Dewey, 1895; James, 1890; Wundt, 1897/1998). The essence of a constructionist approach is the idea that during every moment of waking life, the brain constructs mental states such as emotions, body states, and thoughts by creating situated conceptualizations (Barrett, 2006; Barsalou, 2009) that combine three sources of stimulation: sensory stimulation from the world outside the skin (the exteroceptive sensory array of light and vibrations and chemicals and so on), sensory signals from within the body (somatovisceral stimulation, also called the interoceptive sensory array or the "internal milieu"), and prior experience (also referred to as memory or category knowledge that the brain makes available in part by the re-activation of sensory and motor neurons). These three sources-sensations from the world, sensations from the body, and prior experience-are continually available and the brain networks that process them might be thought of as part of the basic ingredients that form all mental life. Different "recipes" (the combination and weighting of the ingredients) are hypothesized to produce the myriad mental events that people give commonsense names (i.e., "emotions," "cognitions," and "perceptions"). From this perspective, mental categories such as emotions, cognitions, and perceptions are populated by a diverse set of instances that are events to explain, not specific causal processes linked to specific brain regions or networks.

There are three lines of work that support a constructionist functional architecture of mental states. First, there is a growing appreciation in the neuroimaging literature that the same networks have increased activation across a variety of different psychological task domains. For instance, the "default network," including regions of the medial prefrontal cortex, medial temporal lobe, and posterior cingulate cortex, has increased activation during emotion (e.g., Lindquist, Wager, Kober, et al., in press), emotion regulation (e.g., Wager, Davidson, Hughes, Lindquist, \& Ochsner, 2008), representation of the self (e.g., Kelley et al., 2002), mental state attribution to others (e.g., Mitchell, Banaji, \& Macrae, 2005), moral 
reasoning (e.g., Young, Scholz, \& Saxe, in press), episodic memory and prospection (e.g., Addis, Wong, \& Schacter, 2007), semantic processing (e.g., Binder, Desai, Graves, \& Conant, 2009), and even context-sensitive visual perception (Bar et al., 2006). The "salience network," including the insular cortex and anterior midcingulate cortex, has increased activity during emotion (e.g., Lindquist, Wager, Kober, et al., in press), pain (e.g., Lamm, Decety, \& Singer, 2010), anxiety (e.g., Seeley et al., 2007), attention, language (see Nelson et al., 2010), and time perception (see Craig, 2009). Even sensory brain areas that were once thought to be unimodal and domain-specific (such as primary auditory and visual cortices) respond to other sensory domains (e.g., auditory neurons show increased activity during the presentation of visual stimuli; Bizley \& King, 2008; visual neurons show increased activity during the presentation of auditory stimuli; Cate et al., 2009). These findings suggest that lack of support for faculty psychology is not merely an artifact of poor spatial or temporal resolution in neuroimaging techniques.

In fact, meta-analyses that summarize the neuroimaging literature on mental categories such as emotion, the self, memory, etc. confirm that brain regions show little psychological specificity (at least for these categories or for their subordinate categories such as anger, fear, disgust, the autobiographical self, self-referential processing, autobiographical memory, semantic memory, etc.). For instance, our meta-analytic project on emotion demonstrated that the amygdala (previously thought to be specifically related to fear), anterior insula (AI) (previously thought to be specifically related to disgust), anterior midcingulate cortex (aMCC) and orbitofrontal cortex (OFC) (previously thought to be specifically related to sadness and anger, respectively) each showed increased activity across the experience and perception of many different emotions, indicating that increased activity in these areas is not specific to any one emotion category (Lindquist, Wager, Kober, et al., in press). Furthermore, during the experience and perception of emotion, there was increased activity in areas typically involved in autobiographical memory and prospection, language and semantics, and executive control (Barrett, Mesquita, Ochsner, \& Gross, 2007; Kober, et al., 2008; Lindquist, Wager, Kober, et al., in press). Meta-analyses assessing the neural correlates of other mental states demonstrate a similar point. For instance, one meta-analysis found that the same set of midline cortical areas that comprise the "default network" (including the hippocampus, medial prefrontal cortex and posterior cingulate cortex) showed increased activity in memory, prospection for the future, theory of mind, spontaneous thought, and spatial navigation (Spreng, Mar, \& Kim, 2009). Another recent meta-analysis demonstrates that a similar set of regions within the dorsal prefrontal and parietal cortices is involved across working memory, response selection, response inhibition, task switching and cognitive control (Lenartowicz, Kalar, Congdon, \& Poldrack, 2010).

A second line of evidence supporting the viability of a constructionist approach to the mind comes from electrical stimulation and lesion studies. Electrical stimulation of the same site within the human brain produces different mental states across instances (Halgren, Walter, Cherlow, \& Crandall, 1978; Sem-Jacobson, 1968; Valenstein, 1974). Even human lesion studies are consistent with the idea that brain regions are not specific to any one mental state. For instance, the speech disorder called Broca's aphasia is caused by lesions that extend beyond Broca's area, the brain region thought to subserve speech production (Mohr et al., 1978). As another example, amygdala lesions are not specifically associated with deficits in fear-related processing. A patient with bilateral amygdala lesions (i.e., SM) has difficulty perceiving fear on the faces of others (e.g., Adolphs, Tranel, Damasio, \& Damasio, 1994; Adolphs, Tranel, Damasio, \& Damasio, 1995; Adolphs et al., 1999), but more recent findings suggest that patient SM is capable of perceiving fear when her attention is explicitly directed to the eyes of a face (Adolphs et al., 2005) or when viewing caricatures of fearful body postures (Atkinson, Heberlein, \& Adolphs, 2007). These findings suggest that the amygdala might be playing a more general role in attention to novel or 
motivationally relevant stimuli that contribute to fear, but that the amygdala is not specific to fear (for discussions, see Cunningham \& Brosch, in press; Lindquist, Wager, Kober, et al., in press).

Finally, the emerging science of "intrinsic networks" is consistent with the idea that the brain's functional architecture contains networks that correspond to domain-general psychological processes rather than to specific mental state categories. By correlating lowfrequency blood-oxygenation level dependent (BOLD) signal fluctuations in the hemodynamic response of voxels when a brain is "at rest" (i.e., when it is not being probed by an external stimulus or engaging in a directed task), it is possible to identify large-scale distributed networks that span frontal, cingulate, parietal, temporal, and occipital cortices. These networks are highly replicable across studies that use different statistical methods and are observed with both seed-based (e.g., Vincent, Kahn, Snyder, Raichle, \& Buckner, 2008) and other multivariate techniques (e.g., independent component analysis; ICA; Smith et al., 2009) and cluster analysis (Yeo et al., 2011). These intrinsic networks are constrained by anatomical connections (Buckner, 2010; Deco, Jirsa, \& McIntosh, 2010; Fox \& Raichle, 2007; Vincent, et al., 2008), so they seem to reveal something about the functional organization that is fundamental to the human brain. Given that intrinsic activity accounts for a large proportion of the brain's metabolic budget (Raichle \& Minton, 2006), it is possible that these networks might be basic psychological "ingredients" of the mind. Although a number of intrinsic networks have now been identified, none seem to map on to the brain activity that corresponds to the categories in a faculty psychology approach (i.e., there appears to be no one network for "anger" or even "emotion" vs. "cognition").

\subsection{The Present Study}

In this paper, we report a novel study testing a constructionist model of the mind where we measured activity within large-scale distributed brain networks using fMRI as participants generated three kinds of mental states (emotions, body feelings, or thoughts). We then examined the similarity and differences in the pattern of network activity across the three mental states. In our experiment, participants were exposed to a new scenario immersion technique (Wilson-Mendenhall, Barrett, Simmons, \& Barsalou, 2011) that evokes mental events as they happen in everyday life, allowing us to study the sort of subjective experiences that are uniquely human (see also Frith, 2007). Psychology often assumes that mental states emerge only when a person is probed by external stimuli (based on an old model of the mind that was imported from physiology in the 19th century; Danziger, 1997). Yet, mental states do not obey this classic stimulus-response model most of the timepeople do not need a stimulus in the physical world to have a rich and subjectively potent emotion, feeling, or thought (e.g., Killingsworth \& Gilbert, 2010). We tried to do justice to this feature of mental life by using the scenario immersion technique as an ecologically valid method that directs mental content, while keeping some of the unrestrained character of subjective mental experience intact.

Participants heard sensory-rich, vivid, scenarios about unpleasant situations and were asked to create a situated conceptualization during which each situation was experienced as a body state (e.g., heartbeat, touch of an object against the skin, sights, smells, unpleasantness), an emotion (e.g., fear, anger) or a thought (e.g., plan, reflection). At the beginning of each trial, participants were cued to the type of mental state to construct on that trial. Following the cue, participants heard a scenario as they constructed and then elaborated on a body state, emotion, or thought. This imaging method was modeled after Addis and colleagues (2007) who asked participants to "construct" and then "elaborate" on autobiographical memories. We separately analyzed the scenario immersion and the construction + elaboration phases of each trial as two events (scenario immersion, experience). 
Taking a network-based model of the mind as our starting assumption, we hypothesized that mental states were constructed from the interaction of networks (Fuster, 2006; GoldmanRakic, 1988; McIntosh, 2000; Mesulam, 1998; also see Bullmore \& Sporns, 2009), where the psychological function of a set of brain areas exists in the functional interaction of those areas. Specifically, we focused on the seven intrinsic networks recently identified by Yeo and colleagues (2011); these networks were derived from the largest sample of participants $(\mathrm{N}=1000)$ in any study of intrinsic functional connectivity to date and also replicate the networks identified in other published reports (e.g., Fox et al., 2005; Seeley, et al., 2007; Smith et al. 2009; Vincent, et al., 2008). Table 1 lists the brain regions that are found to comprise each network across studies along with key papers that contribute to a functional understanding of each network.

We hypothesized that the so-called "limbic network" supports the brain's ability to generate and/or represent somatovisceral changes that are experienced as the core affective tone that is common to every mental state. Many philosophers and psychologists have proposed that every moment of mental life has some affective aspect (e.g., Wundt, 1897) that can be described as a combination of hedonic pleasure and displeasure with some degree of arousal (Barrett \& Bliss-Moreau, 2009; Russell \& Barrett, 1999). In our constructionist view, we refer to this basic psychological element as "core affect" (Russell, 2003). Although the limbic network outlined by Yeo and colleagues (2011) is limited to a relatively small area of cortex (only covering the ventromedial prefrontal cortex and ventral aspects of the temporal cortex), several subcortical structures are also likely part of this limbic network. For instance, we hypothesize that the nuclei of the basal ganglia are part of a "limbic" network because they are involved in orchestrating effortful behavior (Salamone \& Correa, 2002; Salamone, Correa, Farrar, \& Mingote, 2007) and motor control (Grillner, Hellgren, Menard, Saitoh, \& Wikstrom, 2005). Furthermore, the central nucleus of the amygdala and the midbrain periaqueductal gray might be part of this network insofar that they are respectively involved in producing autonomic responses (for a discussion see Barrett, Mesquita, et al., 2007) and coordinating coherent physiological and behavioral responses (Bandler \& Shipley, 1994; Van der Horst \& Holstege, 1998). It is important to note that the basal ganglia, the amygdala, and the periaqueductal gray all project to the ventromedial prefrontal cortex (vmPFC), which is one of the cortical regions within Yeo et al.'s limbic network.

We hypothesize that the "salience network" (referred to as "ventral attention" by Yeo et al. 2011), uses representations of affect to guide attention and behavior (see Lindquist \& Barrett, under review; Medford \& Critchley, 2010). Importantly, the salience network contains aspects of the dorsal anterior insular cortex and anterior mid-cingulate cortex (aMCC), which are involved in executive attention (Corbetta, Kincade, \& Shulman, 2002; Touroutoglou, Hollenbeck, Dickerson, \& Barrett, in press) and interoception (Critchley, Elliott, Mathias, \& Dolan, 2000; Critchley, Wiens, Rotshtein, Ohman, \& Dolan, 2004), suggesting that this network is an important source of affective attention in the human brain (Barrett \& Bar, 2009; Duncan \& Barrett, 2007). The salience network also contains aspects of the ventral anterior insula that is involved in the experience of affective states (Touroutoglou, et al., in press).

We hypothesize that the "default network" contributes to the representation or "simulation" of previous experience and the retrieval of category knowledge to create situated conceptualizations (i.e., to make meaning of somatovisceral changes in the body in relation to the immediate context). We hypothesize that this network is key to the process of reactivating relevant distributed brain regions to support category knowledge, memories, and prospection of the future by directing sensory and motor regions. Posterior aspects of the default network (e.g., posterior cingulate, precuneus, hippocampus) might be particularly involved in the integration of visuospatial aspects of category knowledge (Cavanna \& 
Trimble, 2006) whereas anterior aspects of the default network (e.g., mPFC) might be involved in integration of the affective, social, and self-relevant aspects of category knowledge (Gusnard et al. 2001).

The "frontoparietal network" plays an executive role by modulating activity in other functional networks (i.e., prioritizing some information and inhibiting other information) to help construct an instance of a mental state. The "dorsal attention network" plays a similar role by directing attention, in particular, to visual information. We hypothesize that during the scenario immersion task, these networks contributed to the executive control processes involved in foregrounding certain types of information in conscious awareness to create one type of mental state over another. For example, although conceptualization is important to all states, it is particularly foregrounded in experiences of emotions and in thoughts. These networks ensure that a mental state is experienced as unified (for a discussion see Lindquist, Wager, Bliss-Moreau, Kober, \& Barrett, in press).

Finally, "visual" and "somatomotor" networks are together involved in the representation of visual, proprioceptive, and auditory sensations. We refer to these as "exteroceptive" sensations because information from outside the body is represented as sounds, smells, tastes, proprioception, and sights. We assume that these sensations are important during the construction of all mental states.

Table 1 includes our hypotheses for each network's involvement in body feelings, emotions, and thoughts. First, we hypothesized that body feelings, emotions, and thoughts would involve some degree of affect, conceptualization, and executive attention (Hypothesis 1). Following this hypothesis, we predicted that the limbic network, the salience network, the default network, and the frontoparietal network would be commonly engaged across a conjunction of all mental states. Second, we hypothesized that a comparison of brain activity across mental states would yield relative differences in the contribution of each ingredient to each kind of state (Hypothesis 2). Specifically, we predicted that body states and emotions engage the limbic and salience networks relatively more than would thoughts (Hypothesis 2a) (see Table 1). We also predicted that thoughts and emotions would engage the default network relatively more than would body states, because we reasoned that conceptualization would play a larger role in mental states where the representation of prior experiences is necessary to make meaning of body sensations in the moment (i.e., emotion) or where representation of prior experiences is being used to guide plans, associations, and reflections about a situation (i.e., thought) (Hypothesis 2b) (see Table 1). Finally, we did not have a priori predictions for how the frontoparietal, dorsal attention, somatomotor, and visual networks would differ across the three classes of mental states.

\section{Method}

\subsection{Participants}

Participants were twenty-one right-handed, native English-speaking adults (12 females, $\mathrm{M}_{\mathrm{age}}=26.42, \mathrm{SD}_{\mathrm{age}}=5.72$ ). Participants gave written informed consent according to the Partners Health Care Institutional Review Board and were paid up to $\$ 200$ for their participation. Potential participants indicated if they had a history of learning disabilities, psychiatric illness, claustrophobia, cognitive dysfunction or alcohol/drug abuse in a phone screening conducted prior to study enrollment. Participants who reported any of these conditions were not enrolled in the study. Participants were also screened for use of psychoactive or systemic medications and for MRI compatibility during this initial phone screening. One participant was disqualified on the day of the study because she had taken migraine medication that morning. The final sample was 20 participants $\left(11\right.$ females, $\mathrm{M}_{\text {age }}=$ $\left.26.40, \mathrm{SD}_{\mathrm{age}}=5.93\right)$. On the day of the experiment, participants also completed the 20-item 
Toronto Alexithymia Scale (TAS-20) (Bagby, Taylor, \& Parker, 1994) and several other self-report measures that are not relevant to the hypotheses discussed in this paper. Alexithymia is a trait characterized by external thinking and difficulty identifying and labeling one's own emotions (Sifneos, 1973). No participants in our sample scored above the cutoff for Alexithymia (cutoff $=61, \mathrm{M}_{\mathrm{TAS}}=38.57 ; \mathrm{SD}_{\mathrm{TAS}}=7.55$ ). This finding ruled out that any of our participants possessed traits that would cause them to have difficulty on our mental state construction task.

\subsection{Procedure}

The present study used a new scenario immersion method developed in our lab and previously used in neuroimaging research (Wilson-Mendenhall, et al. 2011). In this method, participants are presented with scenarios that describe situations from a first person perspective and are asked to imagine each scenario as if they are actually there. The scenarios contain vivid sensory details so that participants can imagine the situation in a multimodal manner, creating experiences that are high in subjective realism. The scenarios used in this study described physical situations involving cars, boats, bikes, hiking, skiing, food, drink, plants, and animals (see Table 2 for examples). Negative scenarios involved a description of physical harm, whereas neutral scenarios described similar physical activities where harm did not occur. The stimulus set consisted of both full scenarios and condensed versions of the same scenarios. The condensed scenarios were shortened versions of the full scenarios that still captured the gist of the situation and were presented during the scanning session due to time limitations (see Table 2 for examples).

The experiment consisted of a training session outside the scanner and a testing session within the scanner (following Wilson-Mendenhall, et al., 2011). Both occurred on the same day. During the training session, participants listened to the scenarios to familiarize themselves with the full scenarios and the condensed scenarios that they would later hear during the scanning session. This procedure was used to enable participants to retrieve the details of the full scenario when presented with the condensed version in the scanner. Participants also received detailed instructions about the construction task during the training session. Participants were told that the construction task was designed to assess the brain basis of different mental experiences. Before they would hear the condensed scenario, a cue would appear to instruct them which mental state they were to create in reaction to the scenario. In the BODY condition, participants were asked to create a body sensation in response to the situation described in the scenario. During the training session, the experimenter gave examples of a variety of internal somatovisceral sensations and instructed the participant how to create and attend to those sensations in reaction to the scenario (see Supplementary Materials for detailed instructions). In the EMOTION condition, participants were asked to create a specific emotion in response to the situation described in the scenario. The experimenter gave examples of several specific emotions (anger, fear, sadness) and instructed the participant how to create and attend to those emotional experiences in reaction to the scenario. In the THOUGHT condition, participants were asked to create a thought in response to the situation described in the scenario. The experimenter explained that a thought involved objectively reviewing a situation and reasoning about what is happening without cultivating any feelings or emotions. We also included a PERCEPTION condition, in which participants were asked to create a sensory perception in response to the situation described in the scenario. The experimenter instructed the participant to take note of the objects in the scene and the relationship between them without analyzing them or having an emotion or feeling. After the researcher ensured that the participant understood the task instructions in the training phase, participants completed 8 practice trials in which they practiced constructing all four mental experiences. 
During the scanning session, participants were presented with 36 negative scenarios and 12 neutral scenarios. Every trial started with a 2 second cue phase to instruct participants which mental state they were to create in reaction to the scenario. The negative scenarios were randomly combined with three different cues so that 12 were experienced as body states, 12 as emotions, and 12 as thoughts. Participants were instructed to experience the 12 neutral scenarios as perceptions, so that they would not habituate to negative scenarios across many presentations. Data from the perception trials were not included during analysis. The task was broken up into three 12.6-minute runs, each presenting 16 scenarios in random fashion. The instructions and scenarios were presented over headphones; the cues and fixation cross were presented on a screen that was made visible through a mirror mounted on the head coil. The task was presented using the stimulus software package 'Presentation' (Neurobehavioral Systems, Inc).

After the cue phase, participants heard a condensed version of the scenario for 10 seconds (scenario immersion phase). During this phase, participants were instructed to use the condensed version to "experience the scenario from the point of view of the particular mental state you were cued with." Following the scenario immersion phase, participants entered the experience phase where they constructed and elaborated on the mental state to experience it as intensely as possible without changing it or thinking about or experiencing anything else. Participants pressed a button to indicate when the mental state had been constructed and that they had begun elaboration (see Addis, et al., 2007). The experience phase (construction + elaboration) was 20 seconds total. After the experience phase ended, participants judged the vividness of their experience and the extent to which they were successful in creating the assigned experience. Ratings were made on a continuous scale from 0 ("not at all") to 10 ("100\%, completely"). The inter-stimulus interval was set at $4 \mathrm{sec}$ during which a fixation cross was displayed in the center of the screen.

\subsection{Imaging details}

The imaging data were collected at the Athinoula A. Martinos Center for Biomedical Imaging using a 3T Siemens Magnetom Trio and a 12-channel matrix head coil. Participants were restricted in head movement through the use of expandable foam cushions and wore MRI-safe headphones through which they heard the scenarios.

Each scanning session started with an automated scout image and shimming procedures. Then, structural T1-weighted multi-echo MEMPRAGE images (van der Kouwe, Benner, Salat, \& Fischl, 2008) were acquired $(\mathrm{TR}=2530 \mathrm{~ms}$, TE1 $=1.64 \mathrm{~ms}$, TE2 $=3.5 \mathrm{~ms}$, TE3= $5.36 \mathrm{~ms}$, TE $4=7.22 \mathrm{~ms}$, flip angle $=7^{\circ}$, with single-shot, interleaved acquisition and a voxel size of $1.0 \times 1.0 \times 1.0 \mathrm{~mm}$ ). After the structural run, a 6-minute resting state functional sequence was acquired, which will not be discussed further in this manuscript. Next, three functional runs followed that each acquired $378 \mathrm{~T} 2 *$ weighted functional volumes $\left(\mathrm{TR}=2000 \mathrm{~ms}, \mathrm{TE}=30 \mathrm{~ms}\right.$, flip angle $=90^{\circ}, \mathrm{FOV}=200 \mathrm{~mm}$, with interleaved slice acquisition and a voxel size of $3.1 \times 3.1 \times 4.0 \mathrm{~mm}$ ). The total duration of the scanning session was a little over an hour. After the functional runs, an 8-minute diffuser sensor imaging (DSI) sequence was acquired, which we do not discuss further.

\subsection{Data analysis}

The functional and structural data was preprocessed and analyzed using Freesurfer 5 (http://surfer.nmr.mgh.harvard.edu/). Structural preprocessing followed the standard Freesurfer protocol for cortical surface and volume reconstruction and parcellation, including automated Talairach transformation, intensity normalization, skull stripping, white matter segmentation and registration to a spherical atlas using a high-dimensional non-linear registration algorithm (Dale, Fischl, \& Sereno, 1999; Fischl, Sereno, \& Dale, 1999; Fischl, 
Sereno, Tootell, \& Dale, 1999). Functional preprocessing included motion correction, spatial smoothing (5mm kernel) and registration of the functional images onto the anatomical scan.

After preprocessing, individual time series were modeled with a canonical hemodynamic response function (gamma function, hemodynamic delay 2.25; dispersion 1.25). The design matrix included motion regressors and second order polynomial nuisance regressors. Timepoints with movement exceeding $2 \mathrm{~mm}$ were excluded from the analysis. A preliminary analysis demonstrated that the experience phase did not show any significant differences between construction and elaboration so we analyzed it as a single 20 -second event (construction + elaboration). We modeled the hemodynamic response function (HRF) for the cue phase, scenario immersion phase, experience phase, and the judgment phase separately. Subsequently, we performed a random effects analysis on the group level to calculate contrast maps.

\subsection{Cortical parcellation}

To identify the seven intrinsic networks of interest in our analysis, we used the surfacebased network labels made available in Freesufer by Yeo and colleagues (2011). These networks were derived from the analysis of resting state data in 1000 healthy young adults. Yeo et al. employed a clustering approach to identify networks of functionally coupled regions across the cerebral cortex. Their 7-network solution was highly consistent across analyses, with $97.4 \%$ of the vertices being assigned to the same network across a discovery and a replication data set. The parcellation of the cortical surface into specific regions was based on the Desikan-Killiany cortical atlas (Desikan et al., 2006). In addition to surfacebased functional analyses, we also report findings from within the subcortical volume using subcortical labels provided by Freesurfer (Fischl et al., 2002).

2.5.1. Hypothesis testing-To investigate Hypothesis 1 that all mental states (body states, emotions, thoughts) would involve some degree of representation of the current state of the body, conceptualization, and executive attention, we estimated the common network engagement for emotions, body feelings, and thoughts during the experience phase with a conjunction analysis. We focused specifically on the experience phase, because in contrast to the scenario immersion phase, there was no external stimulus present in this phase. Hence, the conjunction reflects patterns of activation that are commonly recruited when people generate specific mental content and focus on their internal world without any external stimulation. The conjunction analysis for the scenario immersion phase, which shows common activation during listening to and immersing oneself in a scenario across mental state conditions, is presented in Tables 3-4 in the Supplementary Materials. Each conjunction analysis was implemented by taking the minimum of the absolute value in each vertex across the body focus vs. fixation, emotion vs. fixation and thought vs. fixation contrasts. Subsequently, we identified clusters within the conjunction that spanned at least 100 continuous vertices all reaching a significance threshold of $p<.001$. We also performed a conjunction analysis of the volume, focusing specifically on subcortical structures, identifying clusters that spanned at least 20 continuous voxels all reaching a significance of $p<.0001$ (see Table 4 in Supplementary Materials).

To examine Hypothesis 2 that networks would contribute differentially to each kind of mental state, we first performed region of interest (ROI) analyses using Yeo et al.'s network labels. Each of Yeo et al.'s networks were converted to each participant's individual cortical surface using spherical space as an intermediate registration space. From the resulting seven ROIs, each representing a network of interest, we extracted beta weights (percent signal change) for each contrast comparing a mental state against fixation (scenario immersion and experience separately). These beta weights were analyzed with a one-factor (mental state) 
repeated measures analysis of variance with three levels (body, emotion, thought).

Greenhouse-Geisser corrected tests are presented if the sphericity assumption was not met. Simple effects significant at $p<.05$ are presented in the text when the main effect reached significance.

As another test of Hypothesis 2, we performed contrasts between the three categories of mental states across the whole cortical surface. This allowed us to directly compare mental states without involving a comparison against fixation. Comparisons against fixation may have limited the chance to find differences in engagement of the default network in the conjunction analysis and ROI analysis (see Stark \& Squire, 2001). In addition, whole brain contrasts allowed us to examine whether the ROI results reflected the engagement of one single sub-region within each network, or whether results indeed reflected a distributed network. We localized clusters of activity using the surface-based labels from Yeo et al. (2011) and the surface Desikan-Killiany cortical atlas (Desikan et al., 2006). We compared the three mental state categories across the scenario immersion and the experience phases separately. To correct for multiple comparisons, we performed a semi-automated Monte Carlo simulation implemented in Freesurfer 5. This method performs simulations to produce an estimation of the distribution of maximum cluster size under the null-hypothesis. Following this method, we identified clusters with a vertex-wise threshold of $p<.01$ and a cluster-wise threshold of $p<.05$ (i.e., clusters that have a probability lower than the threshold of $p<.05$ to appear during the null-hypothesis simulation). In addition to clusters on the surface of the brain, we report subcortical clusters with a threshold of $p<.001$ (uncorrected) and a cluster size of $k>20$.

\section{Results}

\subsection{Response time and subjective ratings}

An analysis of the button press response times in seconds demonstrated a significant difference between mental states, $F(2,38)=3.98, p<.05, \eta^{2}=.17$. Simple effects showed that participants constructed bodily feelings $(M=1.95, S D=1.27)$ significantly more quickly than they constructed emotions $(M=2.61, S D=1.28)$ and marginally more quickly than thoughts $(M=2.47, S D=1.48)$. Yet, as expected, participants did not report differences in the ability to construct each type of state. Participants were equally successful in constructing body feelings $(\mathrm{M}=7.2, \mathrm{SD}=1.4)$, emotions $(M=7.3, S D=1.3)$, and thoughts $(M=7.2, S D=1.5)$ during the task, $F(2,38)=.07$, ns. In addition, participants rated their body feelings $(M=7.5, S D=1.2)$, thoughts $(M=7.5, S D=1.1)$ and emotions $(M$ $=7.3, S D=1.1)$ as being equally vivid, $F(2,38)=.47, n s$. There were no sex differences in ratings of the success $\left[\mathrm{M}_{\text {males }}=7.23 ; \mathrm{SD}_{\text {males }}=1.15 ; \mathrm{M}_{\text {females }}=7.17 ; \mathrm{SD}_{\text {females }}=1.65 ; F(1\right.$, $18)=.03, p=.86]$ or vividness $\left[\mathrm{M}_{\text {males }}=7.23 ; \mathrm{SD}_{\text {males }}=.75 ; \mathrm{M}_{\text {females }}=7.37 ; \mathrm{SD}_{\text {females }}=\right.$ $1.50 ; F(1,18)=.07, p=.80]$ of mental state construction. Together, these findings confirm that all participants were able to successfully construct robust and vivid mental states during the scenario immersion procedure.

\subsection{Hypothesis 1: Networks common to emotions, body feelings, and thoughts}

To test Hypothesis 1, we performed a conjunction analysis for the experience phase of the experiment (for an overview of the significant clusters see Table 3). As predicted, we observed common engagement of regions within the salience network (representing affective attention), the default network (conceptualization) and the frontoparietal network (executive control) across all three kinds of mental states (Figure 1). In the salience network, we observed large clusters of activation in the superior frontal gyrus, supplementary motor area (SMA) and the anterior midcingulate cortex (aMCC), bilaterally. Furthermore, we found clusters of activation in the bilateral dorsal anterior insula (AI), bilateral pars 
opercularis (BA 44), and the left temporo-parietal junction (TPJ). In the default network, we observed increased activation within the lateral orbitofrontal cortex and the pars triangularis (BA 45). In the frontoparietal network, we found clusters of activation in the left dorsolateral prefrontal cortex (dlPFC, BA 46). See Supplementary Materials Table 3 for activations observed during scenario immersion.

Contrary to predictions, we did not find common engagement of regions within the cortical limbic network during the experience phase. However, a conjunction analysis targeting subcortical regions revealed common activations in aspects of the basal ganglia hypothesized to comprise the limbic network (left pallidum and putamen) as well as bilateral cerebellum across mental states in the experience phase (see Table 4). Parts of the limbic network, such as the ventromedial prefrontal cortex (vmPFC) and the ventral and medial temporal lobe are especially susceptible to signal dropout because of proximity to the sinuses. A close inspection of these regions in our study indeed showed signal dropout in these areas, which would explain why the cortical aspects of the limbic network did not show robust activation in our analyses. As a result, our hypotheses regarding the role of the cortical limbic regions in mental states could not be fully addressed in the present study.

The conjunction analysis also showed activation in the somatomotor network and the dorsal attention network for which we did not formulate specific predictions. Within the somatomotor network we found a cluster in the left precentral gyrus; within the dorsal attention network we found clusters in the bilateral precentral gyrus and left superior parietal regions.

Notably, we only found deactivations (relative to fixation) in the occipital lobe during the experience phase. This is consistent with our prediction that experiences of emotions, thoughts, and bodily feelings recruit the default network. The absence of significant deactivations in the default network is relevant to this prediction since robust activity in the default network is also observed when participants engage in spontaneous thought during undirected tasks, such as fixation (Andrews-Hanna et al. 2010). See Supplementary Materials Table 3 for deactivations observed during scenario immersion.

\subsection{Hypothesis 2: Relative differences in the involvement of networks across mental states}

3.3.1 Network ROI analyses-To test Hypothesis 2, we performed a ROI analysis using the seven distributed networks as separate ROIs and examined differences in percent signal change extracted from each network across mental state conditions (see Table 5 in the Supplementary Materials for a full overview of the means and standard errors; also see Supplementary Materials Table 1 for a summary of correlations between self-report ratings of success and vividness and percent signal change in the salience network and default network across conditions and Supplementary Materials Table 2 for a discussion of the nonsignificant sex differences in network involvement across the three mental states). All simple effects are significant at $p<.05$ unless explicitly noted. Consistent with Hypothesis 2a that some states would involve a relatively greater contribution of core affect than others, the salience network demonstrated differential activation for emotions and body feelings vs. thoughts. This difference occurred primarily during the scenario immersion phase where we found a significant main effect of mental state in both the left, $F(2,38)=5.33, p<.01, \eta^{2}=$. 22 , and the right hemisphere, $F(2,38)=3.36, p<.05, \eta^{2}=.15$ (see Figure 2). As predicted by Hypothesis $2 \mathrm{a}$, simple effects demonstrated a significantly stronger involvement of the salience network in body feelings and emotions compared to thoughts in the left hemisphere. In the right hemisphere, the comparison between emotions and thoughts reached significance, whereas the comparison between body feelings and thoughts approached significance $(p<.06)$. Furthermore, as predicted, emotions and body feelings did not differ in the degree to which they involved the salience network (all $p>.4$ ). Activation in the 
salience network did not differ between mental state conditions in the experience phase, $F(2$, $38)=.75, p=.45(\mathrm{lh}) ; F(2,38)=.24, p=.70(\mathrm{rh})$.

The cortical aspects of the limbic network ROI did not show any robust differences between the three mental states. We found no differences between conditions during scenario immersion, $F(2,38)=.79, p=.46(\mathrm{lh}) ; F(2,38)=.25, \mathrm{~ns}, p=.73(\mathrm{rh})$. During the experience phase we found a marginally significant main effect of mental state for the left hemisphere, $F(2,38)=2.83, p=.07, \eta^{2}=.13$, but not for the right hemisphere, $F(2,38)=$ $2.13, p=.13$. Simple effects showed significantly stronger engagement of the limbic network in thoughts compared to body feelings. One interpretation of these findings is that participants were not experiencing or representing robust shifts in the peripheral nervous or endocrine systems that are controlled by regions within the limbic network. Another possibility is that the cortical sites of the limbic network (to which this analysis was limited) did not show differential activity across mental states because of signal dropout in the regions comprising Yeo et al.'s limbic network. The whole-brain analyses including subcortical structures are consistent with this latter interpretation since we found relative differences in activity in aspects of the basal ganglia across mental states. We discuss these findings in the whole-brain analyses below.

Consistent with Hypothesis $2 \mathrm{~b}$, the default network was differentially involved across mental states during the experience phase. Both the left hemisphere, $F(2,38)=5.34, p<.01$, $\eta^{2}=.22$, and the right hemisphere, $F(2,38)=4.39, p<.05, \eta^{2}=.19$, demonstrated a significant main effect of mental state (see Figure 2). Simple effects demonstrated a significantly stronger involvement of the default network in thoughts compared to emotions and body feelings across both hemispheres. Emotions and body feelings did not differ from each other in the degree to which they involved the default network (all $p>.5$ ). The default network did not differ between body feelings, emotions and thoughts during scenario immersion, $F(2,38)=1.56, p=.23(\mathrm{lh}) ; F(2,38)=.69, p=.46(\mathrm{rh})$.

The frontoparietal network demonstrated differential activation for emotions, body feelings and thoughts during the scenario immersion phase, specifically in the left hemisphere, $F(2$, $38)=4.63 p<.05, \eta^{2}=.20$. The right hemisphere demonstrated a marginally significant main effect of mental state, $F(2,38)=2.72, p=.09, \eta^{2}=.13, \varepsilon=.78$. Simple effects demonstrated a significant difference between body feelings and thoughts in the left hemisphere, such that there was greater involvement of the frontoparietal network in body feelings than thoughts. This finding could reflect the attention required to focus inward on one's internal sensations while constructing body states. The comparison between body feelings and thoughts in the right hemisphere and between emotions and thoughts in the left hemisphere approached significance $(p=<.09)$. All other simple effects did not reach significance (all $p>.12$ ). Activation in the frontoparietal network did not differ between mental state conditions in the experience phase, $F(2,38)=1.79, p=.18(\mathrm{lh}) ; F(2,38)=.90$, $p=.42(\mathrm{rh})$, suggesting that executive attention contributes equally to mental states once they are constructed.

The dorsal attention network differed between body feelings, emotions and thoughts during the scenario immersion phase, both in the left, $F(2,38)=3.34, p<.05, \eta^{2}=.15$, and the right hemisphere, $F(2,38)=3.62, p=.05, \eta^{2}=.16, \varepsilon=.76$. Simple effects demonstrated that body feelings and emotions had significantly stronger engagement of the dorsal attention network than thoughts in the left hemisphere. In the right hemisphere, emotions differed significantly from thoughts, whereas the comparison between body feelings and thoughts approached significance $(p<.06)$. Emotions and body feelings did not differ from each other in involvement of the dorsal attention network (all $p>.4$ ). These findings suggest that the dorsal attention network plays a role in mental states in which sensory information 
from the body is attended to (i.e., in body states and emotion). They are interesting in that the dorsal attention network has traditionally been associated with executive control processes for exteroceptive sensory information (i.e., visual sensations; see Corbetta \& Shulman, 2002). Activation in the dorsal attention network did not differ between mental state conditions in the experience phase, $F(2,38)=1.27, p=.29(\mathrm{lh}) ; F(2,38)=.79, p=.46$ (rh).

Finally, we found no significant main effects concerning the visual network ROI and the somatomotor network ROIs.

3.3.2 Whole brain analyses-In addition to the ROI analyses, we performed whole brain contrasts to examine the extent to which different sub-regions within each network showed relatively different patterns of activation across mental states. For the scenario immersion phase, the significant clusters per contrast, including the relevant network parcellation(s), are presented in Table 5 and Figure 3. Contrasts with significant clusters in subcortical regions are presented in Table 4. For the experience phase, the significant clusters per contrast, including the relevant network parcellation(s), are presented in Table 6 and Figure 4.

As predicted (Hypothesis 2a), we found that body feelings demonstrated increased activity compared to thoughts in several regions within the salience network that is hypothesized to represent core affective feelings to guide attention and behavior. There were significant clusters of activation bilaterally in the dorsal AI, left vlPFC (including pars opercularis), and bilateral superior frontal gyrus (including the right aMCC) during the scenario immersion phase. Emotions also demonstrated increased activity compared to thoughts within regions of the salience network during scenario immersion (Hypothesis 2a). We found significant clusters in the left vIPFC, the right aMCC (extending into the frontoparietal network), the superior frontal gyrus bilaterally (extending into the dorsal attention network) and the right supramarginal gyrus (extending into the dorsal attention network). Body feelings and emotions did not have increased activity compared to thoughts in regions within the cortical limbic network, although they did have differential activity in some subcortical structures hypothesized to comprise the limbic network. Body feelings had a greater increase in the left thalamus (extending into the pallidum) and the right caudate (extending into the thalamus and pallidum) than did thoughts during the scenario immersion phase. Emotions did not have greater activity than thoughts or body states in any subcortical structures, although they interestingly showed greater activity in the cerebellum than did thoughts. The contrast analysis yielded no significant clusters of activation within the salience network and the limbic network when comparing body feelings to emotions. This finding suggests that a similar degree of core affect is created when someone is attempting to experience a scenario from the point of view of body activity or from the point of view of more specific emotions. Consistent with our predictions, the contrasts comparing thoughts to body feelings and thoughts to emotions did not show any significant clusters within the salience network or the limbic network during the scenario immersion phase.

During the experience phase, body feelings involved stronger engagement of regions within the salience network than emotions, specifically within the left supramarginal gyrus (extending into the frontoparietal network). Since this cluster extended into the frontoparietal network, one interpretation of this finding is that it reflects heightened attentional control as participants continue to experience body states following construction. None of the other contrasts produced significant clusters within the networks supporting core affect. 
In contrast to our predictions, we found no differences in activation within regions of the default network between body feelings, emotions, and thoughts in the scenario immersion phase, except for one cluster in the dmPFC that demonstrated greater activation for emotions than thoughts. Yet, as predicted (Hypothesis $2 b$ ), we observed greater involvement of regions within the default network when we compared thoughts to body feelings in the experience phase. In particular, thoughts involved relatively greater activity in the left and right superior temporal gyrus, the left precuneus, and the left medial prefrontal cortex than body states. Also consistent with Hypothesis $2 b$, we found that thoughts showed stronger activation of regions within the default network than emotions. Significant clusters were present in the left and right superior temporal gyrus and the left medial prefrontal cortex. Finally, and consistent with our predictions (Hypothesis 2b), we found that emotions showed increased activity compared to body feelings in an aspect of the default network, the left anterior temporal lobe. The contrasts comparing body feelings and emotions to thoughts did not show any significant clusters.

We did not have specific predictions for how the frontoparietal network, dorsal attention network, somatomotor network or visual network would contribute differentially to body states v. emotions v. thoughts. During the scenario immersion phase, we found that both body feelings and emotions demonstrated stronger involvement of regions within the frontoparietal network than thoughts, specifically within the dIPFC and superior frontal gyrus. During the experience phase we found a similar effect in regions of the frontoparietal network when comparing body feelings to thoughts, specifically within the supramarginal gyrus and pars triangularis. When comparing thoughts to emotions in the experience phase, we found one significant cluster in the superior frontal gyrus within the frontoparietal network. In terms of the dorsal attention network, we found stronger engagement of the left precentral gyrus when comparing body feelings to thoughts during scenario immersion. Furthermore, emotions demonstrated stronger involvement of the dorsal attention network than thoughts, specifically within the superior parietal lobule, superior frontal gyrus, supramarginal gyrus and the postcentral gyrus. We found two large clusters of activation in temporal regions within the somatosensory network when comparing emotions to body feelings in the scenario immersion phase. Moreover, emotions demonstrated stronger involvement of regions in the somatomotor network than thoughts, specifically within the paracentral and precentral gyrus. Finally, concerning the experience phase, thoughts demonstrated stronger involvement of the postcentral gyrus (somatomotor network) compared to body feelings, and stronger involvement of the left inferior parietal lobe (visual network) compared to emotions. See Table 7 for a summary of findings in support of Hypotheses 1-2.

\section{Discussion}

To our knowledge, the present neuroimaging experiment is the first to explicitly test a constructionist functional architecture of the mind by assessing both similarities and relative differences in the neural correlates of body feelings, emotions, and thoughts. Our findings support the constructionist hypothesis that mental states are best understood by examining relative differences in the engagement of distributed networks that support psychological processes that are engaged to create a variety of mental states. These findings directly call into question the faculty psychology view that different classes of mental states differ categorically at the level of brain organization. In addition, our scenario immersion method provides a new avenue for using fMRI to understand the basic building blocks of the mind.

\subsection{Mental states share common psychological "ingredients"}

We found evidence that body feelings, emotions and thoughts, although subjectively distinct, each involve the participation of the same distributed brain networks that can be 
described in relation to basic psychological processes. Where possible, we have derived knowledge about the function of a network from the literature, but the field is only in the earliest stages of discussing the psychological functions of intrinsic networks. As a result, previous research that provides clear functional descriptions in terms of psychological processes of the networks is scarce (with an exception of the default network; e.g., Buckner \& Carroll, 2007; Schacter, Addis, \& Buckner, 2007; Spreng, et al., 2009). There are, however, many studies about the individual brain areas within each network. In discussion of our findings, therefore, we discuss the functions of the separate regions that comprise the networks to motivate an understanding of the network's involvement, as a whole, in basic psychological process that contributes to all mental states.

4.1.1 Salience network-One of our most notable findings was the common involvement of the salience network across body feelings, emotions, and thoughts. We hypothesized that the salience network supports representations of affective states to guide attention and behavior (Lindquist \& Barrett, under review; Medford \& Critchley, 2010). This hypothesis is consistent with findings that the salience network shows increased activity in tasks requiring the allocation of attention to evocative or behaviorally relevant stimuli (Corbetta, Patel, \& Shulman, 2008; Corbetta \& Shulman, 2002; Nelson, et al., 2010; Seeley, et al., 2007). As identified by Yeo et al., the salience network is comprised of the anterior and midinsula, posterior aspects of the vlPFC (pars opercularis), aspects of the anterior midcingulate cortex (aMCC) and the anterior aspect of the TPJ (supramarginal gyrus). In our study, we found increased activity specifically in the aMCC, supplementary motor area (SMA), the dorsal part of the anterior insula (AI), pars opercularis (BA 44), and the left temporo-parietal junction (TPJ) across all mental states. We will discuss each of these results in turn.

The result that bodily feelings, emotions and thoughts collectively engaged the SMA is consistent with the role of the SMA in internally driven action (Nachev, Kennard, Husain, 2008). This pattern of activity may reflect motor processes associated with the button press through which participants indicated that they had constructed a mental state during the experience phase.

Our finding that the TPJ is engaged across all mental states is consistent with studies that show increased activity during feelings of agency over one's own body (for reviews, see Decety \& Grezes, 2006; Tsakiris, Constantini, \& Haggard, 2008) and when representing someone else's body state (as during empathy Lamm, et al., 2010). Indeed, increased activity in TPJ is often observed when one person engages in theory of mind - or attempts to understand the contents of another's mind-in general (Saxe \& Kanwisher, 2003).

The result that the AI and aMCC were engaged across mental states is consistent with studies that show activation of these regions during interoception (Critchley et al., 2003; Critchley, et al., 2004) and subjective experiences more generally (Craig, 2002, 2009). Indeed, a recent meta-analysis found increased activity in regions comprising Yeo et al.'s salience network (including the AI, aMCC, vlPFC, thalamus and amygdala) during the experience of unpleasant core affect (Hayes \& Northoff, 2011). Another recent paper linked many of these same regions (ventral AI, thalamus, and amygdala) to the experience of affective arousal while viewing negative images (Touroutoglou et al. in press). Our findings were consistent with both these studies in that we found activity in similar regions within the salience network to scenarios that were unpleasant and highly arousing. Our findings thus cannot speak to whether the salience network is involved in all core affective states since we did not include positive scenarios in our study. However, we did find increased activity in aspects of the AI and aMCC to pleasant core affective states in a previous meta-analysis (Wager, Barrett, Bliss-Moreau, Lindquist, Duncan, Kober, et al. 2008), consistent with our hypothesis that regions comprising the salience network are linked to the experience of all 
core affective states. The relative role of the salience network in unpleasant v. pleasant core affect should be the topic of future research.

In terms of our findings concerning the AI, it is important to note that the salience network (called "ventral attention" by Yeo et al., 2011) used in the present study covered both dorsal and ventral aspects. There is some evidence in the literature, however, that the AI can be functionally dissociated into dorsal $\mathrm{v}$. ventral aspects, with dorsal aspects being functionally connected to the aMCC and relatively more involved in tasks where body information is used to guide attention (Kurth, Zilles, Fox, Laird, \& Eickhoff, 2010; Touroutoglou, et al., in press; Wager \& Barrett, 2004). Ventral aspects of the AI, by contrast, are functionally connected to the ventromedial prefrontal cortex and are relatively more involved in tasks where core affective feelings are experienced (Hayes \& Northoff, 2011; Touroutoglou, et al., in press; Wager \& Barrett, 2004). The activations we observed in the AI were primarily in the dorsal portion, which may reflect the role of this area in sustained attention towards salient information (see Lindquist \& Barrett, under review; Medford \& Critchley, 2010; Seeley et al., 2007). Such salience may have been especially important in our immersion task because participants switched attention between different sources of information (e.g., internal sensations v. external sensations) when they actively created mental states.

Our findings suggest that representations of body sensations play a role beyond the experience of physical sensations in the body or affective states such as emotions. In any situation where people are presented with evocative or behaviorally relevant information, the salience network will guide the direction of attention based on body sensations, irrespective of whether people are directed to experience an emotion or objectively think about the situation. This finding is consistent with several recent suggestions in the literature that body cues are a ubiquitous component of mental life, including in states involving perception (Barrett \& Bar, 2009; Cabanac, 2002), judgment (Clore \& Huntsinger, 2007), tasks involving effort (Critchley, et al., 2003), and in consciousness more generally (Craig, 2009; Damasio, 2000). This finding is also consistent with recent research demonstrating that the representation of emotion concepts involves simulations of affective and body states (Oosterwijk, Rotteveel, Fischer, \& Hess, 2009; Oosterwijk, Topper, Rotteveel, \& Fischer, 2010) and with research that suggests that representations of body states are involved when participants understand verbal descriptions of "cognitive" states (e.g., thinking, remembering or sudden insight) (Oosterwijk et al., 2012).

4.1.2 Limbic network-Contrary to our prediction, our findings did not reveal robust activation in the cortical aspects of the limbic network as identified by Yeo et al (2011) during the experience of body feelings, emotions, and thoughts. Our analyses did demonstrate engagement of subcortical parts of the limbic network that are less susceptible to signal drop out, specifically in the pallidum and putamen, however. Research suggesting that the basal ganglia play a role in motivated behavior (Graybiel, 2005, 2008) is consistent with the hypothesis that these structures are involved in the generation of core affective states. For instance, basal ganglia function shows a relationship with symptom severity in disorders in which affect generation is impaired. In particular, the degree of basal ganglia connectivity to other areas within the putative core affect generation network such as ventromedial prefrontal cortex is related to symptom severity in depression (Marchand et al., 2012) and lesions to the basal ganglia result in greater incidence of depression following stroke than lesions elsewhere in the brain (Morris, Robinson, Raphael, \& Hopwood, 1996; Vataja et al., 2004).

The amygdala, another subcortical structure in our putative limbic network, did not have increased activity in our study. Although the amygdala is assumed to be generally involved in emotion, a closer look at the literature reveals that amygdala activity is more likely to 
occur during the sensory perception of behaviorally relevant stimuli than during the internally-focused experience of affective mental states, as occurred in our task (for metaanalyses, see Costafreda et al. 2008; Lindquist et al. in press). Consistent with our findings, a recent study failed to document increased amygdala activity when participants experienced social stress in the scanner (Wager et al. 2009).

4.1.3 Default network-We found common involvement of the default network across mental states, consistent with the hypothesis that this network is necessary for constructing a situated conceptualization that creates a body state, emotion or thought. The hypothesis that the default network supports conceptualization is consistent with the role of the default network in mental state attribution (Mitchell, et al., 2005), emotion experience (Kober, et al., 2008; Lindquist, Wager, Kober, et al., in press), recollection of the autobiographical past (Addis, et al., 2007; Spreng \& Grady, 2010), spontaneous thought (Andrews-Hanna, Reidler, Huang, \& Buckner, 2010) and semantic and conceptual processing (Binder, et al., 2009; Visser, Jefferies, \& Lambon Ralph, 2010). We hypothesize that what unites these disparate domains is the process of conceptualization-in which representations of prior experiences are brought to bear to construct representations of the past, the future, or the present moment. These regions are necessary to give meaning to others' actions, to make meaning of one's own core affective state, to recall prior experiences during instances of memory and spontaneous thought, and to represent the meaning of concepts by simulating category instances (for a discussion, see Lindquist \& Barrett, under review; Lindquist, Wager, Kober, et al., in press).

The default network, as identified by Yeo et al., is comprised of aspects of the medial prefrontal cortex (mPFC), aspects of the pars triangularis and the pars orbitalis, the superior temporal lobe, angular gyrus, and aspects of the precuneus. In our study, we found a common involvement of the lateral orbitofrontal cortex and the pars triangularis (BA 45), across body feelings, emotions, and thoughts. These regions have been particularly associated with semantic processing (Binder et al. 2009; Visser et al. 2010) and may reflect a sub-network (see Yeo et al. 2011, 17-network parcellation; Smith et al. in press) within the default network that specifically supports language (Lindquist \& Barrett, under review; Smith et al. in press). Notably, our conjunction analysis did not yield an increase in activity in the entire default network. Neither, however, did our conjunction analysis yield any significant decreases within core regions of the default network, suggesting that bodily feelings, emotions, and thoughts engaged the default network to the same degree as the spontaneous thought that is observed during fixation (Andrews-Hanna et al. 2010). Since many core regions in the default network (e.g., mPFC, PCC) show increased activation during fixation and thus appear as decreased activity during other tasks (hence the name "default" network; Raichle et al., 2001), we likely placed ourselves at a disadvantage to find a robust increase in the default network during mental state construction by comparing task activity to fixation. Consistent with this interpretation, we found the predicted activation in classic default areas (e.g., mPFC, PCCC) in our contrast analyses (reported below) when we compared one type of mental state to another.

4.1.4 Frontoparietal network-We found common involvement of an aspect of the frontoparietal network across body states, emotions and thoughts, suggesting that all these mental states involve executive attention. Brain areas within this network tend to have increased activity during "top-down control" of attention (Corbetta \& Shulman, 2002), as in "memory maintenance" (Cole \& Schneider, 2007), "rule representation" (Crone, Wendelken, Donohue, \& Bunge, 2006), and "planning" (Fincham, Carter, van Veen, Stenger, \& Anderson, 2002). We hypothesize that this network modulates activity in other functional networks to help construct an instance of a mental state. Activity within this network may reflect the cognitive control needed to instantiate the processes of 
conceptualizing core affect. The frontoparietal network, as identified by Yeo et al., is comprised of aspects of the dorsolateral prefrontal cortex, aspects of the cingulate cortex, the frontoinsula and aspects of the inferior parietal lobule and precuneus. In our study, there was increased activity within the dorsolateral prefrontal cortex across body feelings, emotions, and thoughts.

\subsection{Different profiles or "recipes of ingredients" contribute differently to different mental states}

Although the same distributed brain networks were implicated in body feelings, emotions and thoughts, we also found evidence that different network profiles were associated with each mental state category. Compared to thoughts, body feelings involved relatively greater increases in activity in the salience network (i.e., dorsal anterior insula bilaterally, left vlPFC including pars opercularis, and the right aMCC). Emotions also demonstrated increased activation in the salience network compared to thoughts (i.e., in the left vlPFC, the right aMCC and the right TPJ), albeit in slightly different areas. Additionally, body feelings engaged subcortical regions hypothesized to be involved in core affective generation, such as the thalamus, pallidum, and caudate, to a greater extent than thoughts.

Compared to body feelings, emotions involved relatively greater involvement of the default network, specifically in the left anterior temporal lobe (ATL). Aspects of the ATL are part of the default network and have been linked to the representation of concept knowledge (Binder, et al., 2009; Visser, et al., 2010). These findings imply that the experience of an emotion, as compared to a body state, is characterized by stronger involvement of the process of conceptualization to make meaning of body sensations in the moment. These findings are consistent with behavioral findings demonstrating that concepts like "anger" or "fear" are used to shape body sensations into the experience of an emotion (e.g., Lindquist \& Barrett, 2008a). Similarly, cortical thinning in ATL due to neurodegenerative disease impairs patients' ability to perceive emotional facial expressions as instances of discrete emotional feelings (e.g., anger v. fear) (Lindquist, Gendron, Barrett, \& Dickerson, under review).

Thoughts also demonstrated greater engagement of the default network (bilateral superior temporal gyrus, left precuneus and left mPFC) as compared to body feelings. Furthermore, several regions within the default network, including the left and right superior temporal gyrus and the left mPFC, demonstrated relatively greater increases in activity when participants generated thoughts than when they generated emotions. This finding is consistent with our proposal that conceptualization plays a greater role in mental states where people need to plan, associate, and reflect on a situation (thought) than in a mental state where the focus is on body sensations. Moreover, this finding also suggests that thought may involve the process of conceptualization to a stronger extent than emotion. This interpretation is consistent with the default network's robust involvement in memory and predicting the future (Addis, et al., 2007), theory of mind (Spreng \& Grady, 2010), semantic memory (Binder, et al., 2009; Visser, et al., 2010) and other so-called "cognitive" mental states involving the representation of prior experiences.

The specific combination of activation in regions within the default network and regions within the salience network (as evident from the conjunction analysis) during thought and emotion is consistent with a recent study that demonstrated connectivity between regions of the default network (rTPJ, vmPFC and PCC/precuneus), aspects of the salience network (anterior insula, SMA, aMCC) and the primary sensorimotor cortex during mentalizing tasks (Lombardo et al., 2009). Interestingly, this connectivity pattern occurred both when participants were mentalizing about the self, and when they were mentalizing about others, suggesting an overlap between two processes that have been separated in the literature. 
According to the authors, this pattern of connectivity suggests an interaction between "embodied/simulation based representations" and areas that support "high-level inference based mentalizing." This view is consistent with a constructionist view that representations of sensorimotor and somatovisceral sensations combine with conceptualization to create specific mental content. Future research should assess the degree to which the salience network and default network differ in terms of functional connectivity across emotions vs. body states vs. thoughts. For example, one hypothesis is that seed regions within the salience network and the default network show greater connectivity during emotions and thoughts (which require more conceptualization) compared to body feelings.

Although we did not have a priori hypotheses about the relative involvement of the frontoparietal network across mental states, we did observe that this network was relatively more engaged when people focused on their body feelings than when people generated emotions. This finding provides some insight for a better understanding of disorders that involve extreme body vigilance (e.g., panic disorder and anxiety symptomatology; Schmidt, Lerew, \& Trakowski, 1997). Increased activity in the frontoparietal network could also be interpreted as evidence that participants had more difficulty creating body sensations than creating emotions or thoughts in our task, although their subjective ratings did not support this interpretation.

\subsection{Implications}

The present findings represent a somewhat different functional architecture of the basic building blocks of the human mind than what is assumed in a faculty psychology view. In contrast to traditional faculty psychology approaches that have been popular in cognitive neuroscience over the past three decades, our findings suggest that it is fruitful to take a constructionist framework when attempting to understand how the brain instantiates mental states, in which thoughts and feelings emerge from the combination of intrinsic networks. These networks can be described in terms of basic, domain-general psychological ingredients (such as core affect, conceptualization, executive attention, and exteroceptive sensation) that can be observed as elements across of the variety of mental states that make up the human mind. Our results suggest that as part of this functional architecture, it is productive to focus on broad-scale intrinsic neural networks when interpreting functional neuroimaging data. This idea is consistent with the growing call for a network-based understanding of the brain's functions (Bullmore \& Sporns, 2009; Fuster, 2006; GoldmanRakic, 1988; McIntosh, 2000; Mesulam, 1998; Pessoa, 2008). Our results also emphasize the importance of examining distributed patterns of brain activation to understand mental states with different content, rather than focusing on single regions. In the most extreme version of this approach, psychological function exists as the functional interaction of those areas, so that isolated regions serve different psychological functions depending on what they are connected to during a given instance. In future directions, it will be important to use multivariate methods (e.g., McIntosh, Bookstein, Haxby, \& Grady, 1996), functional connectivity analyses, and other neuroinformatic approaches that allow researchers to understand how individual brain regions are working together to instantiate basic psychological processes during mental states.

Second, the present findings shed new light on the function of specific brain regions as they contribute to broad-scale functional networks. For example, we found increased activation in the area known as the TPJ across all mental states in our study. Yet, TPJ is sometimes referred to as the "neural correlate" of perceiving other's minds with the assumption that it consistently and specifically performs a neural computation for theory of mind (Saxe \& Kanwisher, 2003; Young, Cushman, Hauser, \& Saxe, 2007). Our findings suggest that TPJ is unlikely to play such a specific role (for a similar view see Mitchell, 2008), since aspects of it (e.g., supramarginal gyrus) are part of the larger salience network in which we observed 
increased activity during the generation of one's own mental states (rather than just reflecting on other's experiences) (for another discussion, see Decety \& Grezes, 2006). If the salience network (including the TPJ) is engaged (at least in part) in the representation of core affect, then this would explain its involvement across tasks involving both the generation and perception of mental states. In studies of mental state perception in others (i.e., theory of mind), TPJ might have increased activity because other people are salient stimuli (and hence are represented as having core affective value) (Mitchell, 2008).

Alternatively, simulations of another person's core affective state may be necessary when trying to understand what they are thinking and feeling (i.e., theory of mind relies on embodiment of affective states; Lombardo, et al., 2009). Still other aspects of the TPJ (angular gyrus) are part of the default network involved in conceptualizing. One possibility is that the role of TPJ depends on its "neural context," in which a brain area's function depends on the other areas to which it is functionally connected at a given point in time (e.g., McIntosh, 2000). Another possibility is that there are different functional sub-regions of TPJ that separately contribute to core affect and conceptualization. This framework for understanding a brain area's function also applies to other areas that showed increased activity in our study (e.g., MPFC, aMCC, insula) that have been attributed to specific mental states in the literature (e.g., self-referential processing; Kelley, et al., 2002; e.g., conflict; Kerns, 2004; e.g., disgust; Wicker, et al., 2003).

\subsection{Limitations}

The findings of the present study produced questions that could be the topic of future research. For example, an unexpected finding was that differences between mental states occurred across different phases of the experimental task. For instance, differences in activity within the salience network were most pronounced between mental states when participants were immersing themselves in the scenario. By contrast, the experience phase did not show differences within the salience network between body feelings, emotions, and thoughts, suggesting that all mental states involved affective processes to the same extent during the experience phase. It is possible to understand these results by considering that bodily feelings where constructed faster than were emotions and thoughts. Participants might have started the construction of bodily feelings early in the immersion phase, corresponding to a stronger engagement of the salience network during immersion and a shorter response time during the experience phase. Nevertheless, this interpretation does not explain the stronger engagement of the salience network during the immersion phase for emotions. Another possible interpretation of this finding is that cueing participants to experience a body state or emotion caused them to attend to the body and affective details of a scenario at the exclusion of other details whereas in thought they attended to the non-body/ affective details. We cannot rule out this interpretation given the parameters of the study design. One means of clarifying this question in future studies would be to prevent participants from seeing the cue until after they hear the scenario. Yet a third interpretation of this finding is that body feelings and emotions engage the salience network more so than thought, but only during the initial moments of the experience (e.g., when it is initially being constructed) and not as the experience persists over time. That is, the relative involvement of different distributed networks during the production of mental states may not be dependent on the type of mental state alone-it may also depend on the time course of the state. This question is the topic of future research.

Another finding from the present study that deserves more experimental attention is the finding that body states and thoughts were more distinct from one another than they were each from emotions. Although it is possible that our emotion manipulation was just less robust than the other experimental conditions, or that participants did not adequately create emotions in reaction to the scenarios, this interpretation is not supported by our self-report 
findings. Participants reported that they had just as much success creating emotions as body states and thoughts, and that they experienced emotions just as vividly as other states. Future studies should ask participants to rate the specificity with which they experienced each state on a trial-by-trial basis. A final interpretation of this finding, and the one predicted a priori by our constructionist view, is that, by design (rather than by experimental failure), emotions share many of the "ingredients" that also comprise both body states and thoughts. We have proposed (Barrett, 2006) and demonstrated (Lindquist \& Barrett, 2008a) elsewhere that emotions are states that are at once affective and conceptual. Future studies should continue to explore the extent to which emotions are mental states that consist of both affective and conceptual ingredients.

Finally, a limitation of the present study is that it did not measure individual differences in cognitive abilities that might have constrained participants' ability to construct mental states. One hypothesis of a constructionist framework is that individuals with greater working memory capacity will be better able to access relevant conceptual information and inhibit irrelevant conceptual information during the construction of mental states (Barrett, Tugade \& Engel, 2004; Lindquist \& Barrett, 2008b). In the future, it would thus be interesting to model the extent to which individuals with greater working memory capacity are not only more successful at such a task, but also more likely to have discrete and robust mental states in general.

\subsection{Future Directions}

In the present paper, we attempted to describe each intrinsic network in psychological terms. It is important to acknowledge that these psychological descriptions are a first hypothesis and are only a starting point. In future research, it will be important to continue to define and refine the constructionist framework that we have laid out in this paper and elsewhere (Barrett, 2006, 2009; Barrett et al., 2007; Barrett, Lindquist, \& Gendron, 2007; Barrett, Mesquita, et al., 2007; Lindquist \& Barrett, 2008a, 2008b; Lindquist, Wager, Bliss-Moreau, et al., in press; Lindquist, Wager, Kober, et al., in press; Wilson-Mendenhall, et al., 2011). The best psychological descriptions for existing networks will no doubt change as data accrues over time. Perhaps the goal moving forward is to describe the psychologically most basic "common denominators" that will link a range of findings across task domains that appear very different on the surface (cf., Lindquist \& Barrett, under review). For example, defining the salience network as a functional group that represents core affective information from the body to guide attention and behavior not only explains the role of this network in emotion, but also in focal attention, performance monitoring, language, sensory processing, and consciousness more generally (for reviews see Craig, 2009; Nelson, et al., 2010). It is important to note that a constructionist framework does not merely rename networks to fit one particular theoretical view. Instead, it attempts to provide functional descriptions of distributed networks that distill many years of neuroimaging research on emotion, memory, thought, semantics and so on, to shed new light on how the mind maps onto the brain.

Analysis of intrinsic networks remains an important direction of future research as the science attempts to identify the most basic common denominators of psychological experience. For example, explicitly modeling time has allowed researchers to identify spatially distinct intrinsic networks that are also maximally distinct in terms of their temporal dynamics (Smith et al., in press). Smith et al. demonstrate, for example, that the default network can be further parsed into temporally-defined sub-networks that might each have distinct psychological functions (e.g., language v. representing prior experiences). With such refinements, researchers will be better equipped to discover the building blocks of mental states. 
Finally, although a construction approach is still underspecified, and further elaboration and refinement is crucial, our findings add to a growing literature suggesting that faculty psychology should be discarded as a scientific framework for understanding how the brain creates the mind. The findings from our study demonstrate that the brain cannot be parsed into different territories for different mental faculties that map to unique mental experiences in a one-on-one fashion. As emergent phenomenon, mental states with distinct phenomenology, such as body feelings, emotions and thoughts are not necessarily localized to distinct regions (or even networks) within the human brain. Humans have the capacity to experience a wide variety of mental states, and it is only by studying this variety that we will be able to finally understand the basic building blocks that constitute them.

\section{Supplementary Material}

Refer to Web version on PubMed Central for supplementary material.

\section{Acknowledgments}

Many thanks to Thomas Yeo, Fenna Krienen, and the Buckner lab for making the Yeo et al. (2011) network parcellation available. This research was supported by a National Institutes of Health Director's Pioneer award (DP1OD003312) to Lisa Feldman Barrett. The writing of this manuscript was supported by a Marie Curie International Outgoing Fellowship awarded by the Seventh Framework Program of the European Commission to Suzanne Oosterwijk and a Harvard University Mind/Brain/Behavior Postdoctoral Fellowship to Kristen Lindquist.

\section{References}

Addis DR, Wong AT, Schacter DL. Remembering the past and imagining the future: Common and distinct neural substrates during event construction and elaboration. Neuropsychologia. 2007; 45(7): 1363-1377. [PubMed: 17126370]

Adolphs R, Gosselin F, Buchanan TW, Tranel D, Schyns P, Damasio AR. A mechanism for impaired fear recognition after amygdala damage. Nature. 2005; 433(7021):68-72. [PubMed: 15635411]

Adolphs R, Tranel D, Damasio H, Damasio A. Impaired recognition of emotion in facial expressions following bilateral damage to the human amygdala. Nature. 1994; 372(6507):669-672. [PubMed: 7990957]

Adolphs R, Tranel D, Damasio H, Damasio AR. Fear and the human amygdala. Journal of Neuroscience. 1995; 15(9):5879-5879. [PubMed: 7666173]

Adolphs R, Tranel D, Hamann S, Young AW, Calder AJ, Phelps EA, et al. Recognition of facial emotion in nine individuals with bilateral amygdala damage. Neuropsychologia. 1999; 37(10): 1111-1117. [PubMed: 10509833]

Andrews-Hanna JR, Reidler JS, Huang C, Buckner RL. Evidence for the default network's role in spontaneous cognition. Journal of Neurophysiology. 2010; 104(1):322-322. [PubMed: 20463201]

Atkinson AP, Heberlein AS, Adolphs R. Spared ability to recognise fear from static and moving whole-body cues following bilateral amygdala damage. Neuropsychologia. 2007; 45(12):27722782. [PubMed: 17561172]

Bagby RM, Taylor GJ, Parker JDA. The twenty-item Toronto Alexithymia Scale: II. Convergent, discriminant, and concurrent validity. Journal of Psychosomatic Research. 1994; 38:33-40. [PubMed: 8126688]

Bandler R, Shipley MT. Columnar organization in the midbrain periaqueductal gray: modules for emotional expression? Trends in Neurosciences. 1994; 17(9):379-389. [PubMed: 7817403]

Bar M. Visual objects in context. Nature Reviews Neuroscience. 2004; 5:617-629.

Bar M, Kassam KS, Ghuman AS, Boshyan J, Schmid AM, Dale AM, et al. Top-down facilitation of visual recognition. Proceedings of the National Academy of Sciences. 2006; 103(2):449-449.

Barrett LF. Solving the emotion paradox: Categorization and the experience of emotion. Personality and Social Psychology Review. 2006; 10(1):20-20. [PubMed: 16430327] 
Barrett LF. The Future of Psychology: Connecting Mind to Brain. Perspectives on Psychological Science. 2009b; 4:326-339. [10.1111/j.1745-6924.2009.01134.x]. [PubMed: 19844601]

Barrett LF. Bridging token identity theory and supervenience theory through psychological construction. Psychological Inquiry. 2011; 22(2):115-127. [PubMed: 21785534]

Barrett, LF. Emotions are real. Emotion. (in press)

Barrett LF, Bar M. See it with feeling: Affective predictions in the human brain. Philosophical Transactions of the Royal Society of London: Series B. Biological Sciences. 2009; 364:13251334.

Barrett LF, Bliss-Moreau E. Affect as a psychological primitive. Advances in Experimental Social Psychology. 2009; 41:167-218. [PubMed: 20552040]

Barrett LF, Lindquist KA, Bliss-Moreau E, Duncan S, Gendron M, Mize J, Brennan L. Of mice and men: Natural kinds of emotions in the mammalian brain? A response to Panksepp and Izard. Perspectives on psychological science: a journal of the Association for Psychological Science. 2007; 2(3):297-297. [PubMed: 19079552]

Barrett LF, Lindquist KA, Gendron M. Language as context for the perception of emotion. Trends in Cognitive Sciences. 2007; 11(8):327-332. [PubMed: 17625952]

Barrett LF, Mesquita B, Ochsner KN, Gross JJ. The experience of emotion. Annual review of psychology. 2007; 58:373-373.

Barrett LF, Tugade MM, Engle RW. Individual differences in working memory capacity and dualprocess theories of the mind. Psychological Bulletin. 2004; 130:553-573. [PubMed: 15250813]

Barsalou LW. Simulation, situated conceptualization, and prediction. Philosophical Transactions of the Royal Society of London: Biological Sciences. 2009; 364:1281-1289.

Bartels A, Zeki S. The neural basis of romantic love. Neuroreport. 2000; 11:3829-3834. [PubMed: 11117499]

Binder JR, Desai RH, Graves WW, Conant LL. Where is the semantic system? A critical review and meta-analysis of 120 functional neuroimaging studies. Cerebral Cortex. 2009; 19(12):2767-2796. [PubMed: 19329570]

Bizley JK, King AJ. Visual-auditory spatial processing in auditory cortical neurons. Brain Research. 2008; 1242:24-36. [PubMed: 18407249]

Buckner RL. The role of the hippocampus in prediction and imagination. Annual Review of Psychology. 2010; 61:27-48.

Buckner RL, Carroll DC. Self-projection and the brain. Trends in Cognitive Sciences. 2007; 2:49-57. [PubMed: 17188554]

Bullmore E, Sporns O. Complex brain networks: Graph theoretical analysis of structural and functional systems. Nature Review Neuroscience. 2009; 10(3):186-198.

Cabanac M. What is emotion? Behavioural Processes. 2002; 60(2):69-83. [PubMed: 12426062]

Cate AD, Herron TJ, Yund W, Stecker C, Rinner T, Kang X, et al. Auditory Attention Activates Peripheral Visual Cortex. PLOS One. 2009; 4(2)

Cavanna AE, Trimble M. The precuneus: a review of its functional anatomy and behavioural correlates. Brain. 129:564-583. [PubMed: 16399806]

Clore GL, Huntsinger JR. How emotions inform judgment and regulate thought. Trends in Cognitive Sciences. 2007; 11:393-399. [PubMed: 17698405]

Cole MW, Schneider W. The cognitive control network: Integrated cortical regions with dissociable functions. Neuroimage. 2007; 37(1):343-360. [PubMed: 17553704]

Corbetta M, Kincade JM, Shulman GL. Neural systems for visual orienting and their relationships to spatial working memory. Journal of Cognitive Neuroscience. 2002; 14(3):508-523. [PubMed: 11970810]

Corbetta M, Patel G, Shulman GL. The reorienting system of the human brain: From environment to theory of mind. Neuron. 2008; 58(3):306-324. [PubMed: 18466742]

Corbetta M, Shulman GL. Control of goal-directed and stimulus-driven attention in the brain. Nature Reviews Neuroscience. 2002; 3(3):215-229. 
Costafreda SG, Brammer MJ, David AS, Fu CHY. Predictors of amygdala activation during the processing of emotional stimuli: A meta-analysis of 385 PET and fMRI studies. Brain Research Reviews. 2008; 58:57-70. [PubMed: 18076995]

Craig AD. How do you feel? Interoception: the sense of the physiological condition of the body. Nature Reviews. Neuroscience. 2002; 3(8):655-666.

Craig AD. How do you feel--now? The anterior insula and human awareness. Nature Reviews Neuroscience. 2009; 10(1):59-70.

Critchley HD, Elliott R, Mathias CJ, Dolan RJ. Neural activity relating to generation and representation of galvanic skin conductance responses: a functional magnetic resonance imaging study. The Journal of Neuroscience. 2000; 20(8):3033-3040. [PubMed: 10751455]

Critchley HD, Mathias CJ, Josephs O, O’Doherty J, Zanini S, Dewar BK, et al. Human cingulate cortex and autonomic control: converging neuroimaging and clinical evidence. Brain. 2003; 126:2139-2152. [PubMed: 12821513]

Critchley HD, Wiens S, Rotshtein P, Ohman A, Dolan RJ. Neural systems supporting interoceptive awareness. Nature Neuroscience. 2004; 7(189-195)

Crone EA, Wendelken C, Donohue SE, Bunge SA. Neural evidence for dissociable components of task-switching. Cerebral Cortex. 2006; 16:475-486. [PubMed: 16000652]

Cunningham WA, Brosch T. Motivational salience: Amygdala tuning from traits, needs, values, and goals. Current Directions in Psychological Science. (in press).

D'Esposito M, Aguirre GK, Zarahn E, Ballard D, Shin RK, Lease J. Functional MRI studies of spatial and nonspatial working memory. Cognitive Brain Research. 1998; 7:1-13. [PubMed: 9714705]

Dale AM, Fischl B, Sereno MI. Cortical surface-based analysis. I. Segmentation and surface reconstruction. Neuroimage. 1999; 9(2):179-194. [PubMed: 9931268]

Damasio, A. The Feeling of What Happens: Body and Emotion in the Making of Consciousness. Harvest Books; 2000.

Danziger, K. Naming the mind: How psychology found its language. Sage Publications Ltd; New York: 1997.

Decety J, Grezes J. The power of simulation: Imagining one's own and other's behavior. Brain Research. 2006; 1079(4-14)

Deco G, Jirsa VK, McIntosh AR. Emerging concepts for the dynamical organization of resting-state activity in the brain. Nature Reviews Neuroscience. 2010; 12(1):43-56.

Desikan RS, Segonne F, Fischl B, Quinn BT, Dickerson BC, Blacker D, et al. An automated labeling system for subdividing the human cerebral cortex on MRI scans into gyral based regions of interest. Neuroimage. 2006; 31(3):968-980. [PubMed: 16530430]

Dewey J. The theory of emotion. Psychological Review. 1895; 2(1):13-13.

Dosenbach NU, Visscher KM, Palmer ED, Miezin FM, Wenger KK, Kang HC, Burgund ED, Grimes AL, Schlaggar BL, Petersen SE. A core system for the implementation of task sets. Neuron. 2006; 50:799-812. [PubMed: 16731517]

Dosenbach NUF, Fair DA, Cohen AL, Schlaggar BL, Petersen SE. A dual-networks architecture of top-down control. Trends in Cognitive Sciences. 2008; 12(3):99-105. [PubMed: 18262825]

Duncan S, Barrett LF. Affect is a form of cognition: A neurobiological analysis. Cognition and Emotion. 2007; 21:1184-1211. [PubMed: 18509504]

Eickhoff SB, Lotze M, Wietek B, Amunts K, Enck P, Zilles K. Segregation of visceral and somatosensory afferents: An fMRI and cytoarchitectonic mapping study. Neuroimage. 2006

Engel SA, Rumelhart DE, Lee AT, Glover GH, Chichilnisky E-J, Shadlen MN. fMRI of human visual cortex. Nature. 1994; 369(525)

Fan J, Bruce T, McCandliss D, Fossella JA, Flombaum JI, Posner MI. The activation of attentional networks. NeuroImage. 2005; 26:471-479. [PubMed: 15907304]

Fincham JM, Carter CS, van Veen V, Stenger A, Anderson JR. Neural mechanisms of planning: A computational analysis using event-related fMRI. Proceedings of the National Academy of Sciences. 2002; 99:3346-3351. 
Fischl B, Salat DH, Busa E, Albert M, Dieterich M, Haselgrove C, et al. Whole brain segmentation: automated labeling of neuroanatomical structures in the human brain. Neuron. 2002; 33(3):341355. [PubMed: 11832223]

Fischl B, Sereno MI, Dale AM. Cortical surface-based analysis. II: Inflation, flattening, and a surfacebased coordinate system. Neuroimage. 1999; 9(2):195-207. [PubMed: 9931269]

Fischl B, Sereno MI, Tootell RB, Dale AM. High-resolution intersubject averaging and a coordinate system for the cortical surface. Hum Brain Mapp. 1999; 8(4):272-284. [PubMed: 10619420]

Fox MD, Raichle ME. Spontaneous fluctuations in brain activity observed with functional magnetic resonance imaging. BOLD. 2007; 1:0-5.

Fox MD, Snyder AZ, Vincent JL, Corbetta M, Van Essen DC, Raichle ME. The human brain is intrinsically organized into dynamic, anticorrelated functional networks. Proceedings of the National Academy of Sciences. 2005; 102(27):9673-9678.

Frith, C. Making up the mind: How the brain creates our mental world. John Wiley \& Sons; New York: 2007.

Fuster JM. The cognit: a network model of cortical representation. International Journal of Psychophysiology. 2006; 60(2):125-132. [PubMed: 16626831]

Gendron M, Barrett LF. Reconstructing the past: A century of ideas about emotion in psychology. Emotion Review. 2009; 1(4):316-316. [PubMed: 20221412]

Greene JD, Sommerville RB, Nystrom LE, Darley JM, Cohen JD. An fMRI investigation of emotional engagement in moral judgment. Science. 2001; 293(5537):2105-2105. [PubMed: 11557895]

Goldman-Rakic PS. Topography of cognition: Parallel distributed networks in primate association cortex. Annual Review of Neuroscience. 1988; 11:137-156.

Gonsalves BD, Cohen NJ. Brain imaging, cognitive processes, and brain networks. Perspectives on Psychological Science. 2010; 5:744-752.

Graybiel AM. The basal ganglia: learning new tricks and loving it. Current Opinion in Neurobiology. 2005; 15:638-644. [PubMed: 16271465]

Graybiel AM. Habits, rituals, and the evaluative brain. Annual Review of Neuroscience. 2008; 31:359-387.

Grillner S, Hellgren J, Menard A, Saitoh K, Wikstrom MA. Mechanisms for selection of basic motor programs--roles for the striatum and pallidum. Trends in Neurosciences. 2005; 28(7):364-370. [PubMed: 15935487]

Grossman M, Smith EE, Koenig P, Glosser G, DeVita C, Moore P, McMillan C. The Neural Basis for Categorization in Semantic Memory. NeuroImage. 2002; 17:1549-1561. [PubMed: 12414293]

Gusnard DA, Akbudak E, Shulman GL, Raichle ME. Medial prefrontal cortex and self-referential mental activity: Relation to a default mode of brain function. Proceedings of the National Academy of Sciences. 2001; 98:4259-4264.

Halgren E, Walter RD, Cherlow DG, Crandall PH. Mental phenomena evoked by electrical stimulation of the human hippocampal formation and amygdala. Brain. 1978; 101(1):83-83. [PubMed: 638728]

Harlow HF, Stagner R. Psychology of feelings and emotions. I. Theory of feelings. Psychological Review. 1932; 39(6):570-589.

Hayes DJ, Northoff G. Identifying a network of brain regions involved in aversion-related processing: A cross-species translational investigation. Frontiers in Integrative Neuroscience. 2011; 5:1-21. [PubMed: 21369403]

James, W. The principles of psychology. Vol. Vol. 1. Holt; New York: 1890.

Kanwisher N, McDermott JF, Chun MM. The Fusiform Face Area: A Module in Human Extrastriate Cortex Specialized for Face Perception. Journal of Neuroscience. 1997; 17:4302-4311. [PubMed: 9151747]

Kelley WM, Macrae CN, Wyland CL, Caglar S, Inati S, Heatherton TF. Finding the Self ? An EventRelated fMRI Study. Journal of Cognitive Neuroscience. 2002; 14:785-794. [PubMed: 12167262]

Kerns J. Anterior cingulate conflict monitoring and adjustments in control. Science. 2004; 303:1023. [PubMed: 14963333] 
Kober H, Barrett LF, Joseph J, Bliss-Moreau E, Lindquist KA, Wager TD. Functional grouping and cortical-subcortical interactions in emotion: a meta-analysis of neuroimaging studies. Neuroimage. 2008; 42(2):998-1031. [PubMed: 18579414]

Killingsworth MA, Gilbert DT. A wandering mind is an unhappy mind. Science. 2010; 330:932. [PubMed: 21071660]

Kurth F, Zilles K, Fox PT, Laird AR, Eickhoff SB. A link between the systems: functional differentiation and integration within the human insula revealed by meta-analysis. Brain Structure and Function. 2010; 214:519-534. [PubMed: 20512376]

Lamm C, Decety J, Singer T. Meta-analytic evidence for common and distinct neural networks associated with directly experienced pain and empathy for pain. NeuroImage. 2010; 54:24922502. [PubMed: 20946964]

Lenartowicz A, Kalar DJ, Congdon E, Poldrack RA. Towards an ontology of cognitive control. Topics in Cogntiive Science. 2010; 2:678-692.

Lindquist KA, Barrett LF. Constructing emotion: The experience of fear as a conceptual act. Psychological Science. 2008a; 19(9):898-898. [PubMed: 18947355]

Lindquist, KA.; Barrett, LF. Emotional complexity. In: Lewis, M.; Haviland-Jones, JM.; Barrett, LF., editors. Handbook of Emotions. 3 ed. Guilford; New York: 2008b.

Lindquist KA, Barrett LF. Mapping mind to brain: Crafting a mental ontology for cognitive neuroscience. (under review).

Lindquist KA, Gendron M, Barrett LF, Dickerson BC. Emotion, but not affect perception, is impaired with semantic memory loss. (under review).

Lindquist KA, Wager TD, Bliss-Moreau E, Kober H, Barrett LF. What are emotions and where are they in the brain? Behavioral and Brain Sciences. (in press).

Lindquist KA, Wager TD, Kober H, Bliss E, Barrett LF. The brain basis of emotion: A meta-analytic review. Behavioral and Brain Sciences. (in press).

Lombardo MV, Chakrabarti B, Bullmore ET, Wheelwright SJ, Sadek SA, Suckling J, et al. Shared neural circuits for mentalizing about the self and others. Journal of Cognitive Neuroscience. 2009

Marchand WR, Lee JN, Johnson S, Thatcher J, Gale P, Wood N, Jeong E-K. Striatal and cortical midline circuits in major depression: Implications for suicide and symptom expression. Progress in Neuro-Psychopharmacology \& Biological Psychiatry. 2012; 36:290-299. [PubMed: 22079109]

McIntosh AR. Towards a network theory of cognition. Neural Networks. 2000; 13:861-870. [PubMed: 11156197]

McIntosh AR, Bookstein FL, Haxby JV, Grady CL. Spatial pattern analysis of functional brain images using partial least squares. Neuroimage. 1996; 3(3):143-157. [PubMed: 9345485]

Medford N, Critchley HD. Conjoint activity of anterior insula and anterior cingulate cortex: Awareness and response. Brain Structure and Function. 2010; 214:535-549. [PubMed: 20512367]

Mesulam MM. From sensation to cognition. Brain. 1998; 121(6)):1013-1013. [PubMed: 9648540]

Mitchell J. Activity in right temporo-parietal junction is not selective for theory-of-mind. Cerebral Cortex. 2008; 18:262-271. [PubMed: 17551089]

Mitchell J, Banaji MR, Macrae CN. The link between social cognition and self-referential thought in the medial prefrontal cortex. Journal of Cognitive Neuroscience. 2005; 17(8):1306-1315. [PubMed: 16197685]

Mohr JP, Pessin MS, Finkelstein S, Funkenstein HH, Duncan GW, Davis KR. Broca aphasia: Pathologic and clinical. Neurology. 1978; 28:311. [PubMed: 565019]

Morosan P, Rademacher J, Schleicher A, Amunts K, Schormann T, Zilles K. Human primary auditory cortex: Cytoarchitectonic subdivisions and mapping into a spatial reference system. Neuroimage. 2001; 13:684-701. [PubMed: 11305897]

Morris PL, Robinson RG, Raphael B, Hopwood MJ. Lesion location and poststroke depression. Journal of Neuropsychiatry and Clinical Neuroscience. 1996; 8:399-403.

Nachev P, Kennard C, Husain M. Functional role of the supplementary and pre-supplementary motor areas. Nature Reviews Neuroscience. 2008; 9:856-869. 
Nelson SM, Dosenbach NU, Cohen AL, Wheeler ME, Schlaggar BL, Petersen SE. Role of the anterior insula in task-level control and focal attention. Brain Struct Funct. 2010; 214(5-6):669-680. [PubMed: 20512372]

Northoff G, Bermpohl F. Cortical midline structures and the self. Trends in Cognitive Sciences. 2004; 8:102-107. [PubMed: 15301749]

Oosterwijk S, Rotteveel M, Fischer AH, Hess U. Embodied emotion concepts: How generating words about pride and disappointment influences posture. European Journal of Social Psychology. 2009; 39:457-466.

Oosterwijk S, Topper M, Rotteveel M, Fischer AH. When the mind forms fear: Embodied fear knowledge potentiates bodily reactions to fearful stimuli. Social Psychological and Personality Science. 2010; 1:65-72.

Oosterwijk S, Winkielman P, Pecher D, Zeelenberg R, Rotteveel R, Fischer AH. Mental states inside out: Switching costs for emotional and non-emotional sentences that differ in internal and external focus. Memory and Cognition. 2012; 40:93-100.

Pessoa L. On the relationship between emotion and cognition. Nature Reviews Neuroscience. 2008; 9(2):148-158.

Poldrack RA. Mapping mental function to brain structure: How can cognitive neuroimaging succeed? Perspectives on Psychological Science. 2010; 5:753-761.

Raichle ME, MacLeod AM, Snyder AZ, Powers WJ, Gusnard DA, Shulman GL. A default mode of brain function. Proceedings of the National Academy of Sciences. 2001; 98(2):676-676.

Raichle ME, Minton MA. Brain work and brain imaging. Annual Review of Neuroscience. 2006; 29:449-476.

Rugg MD, Otten LJ, Henson RN. The neural basis of episodic memory: evidence from functional neuroimaging. Philosophical Transactions of the Royal Society, London, B Biological Sciences. 2002; 357(1424):1097-1110. doi: 10.1098/rstb.2002.1102.

Russell JA. Core affect and the psychological construction of emotion. Psychological Review. 2003; 110(1):145-145. [PubMed: 12529060]

Russell JA, Barrett LF. Core affect, prototypical emotional episodes, and other things called emotion: dissecting the elephant. Journal of Personality and Social Psychology. 1999; 76(5):805-819. [PubMed: 10353204]

Sakai K, Passingham RE. Prefrontal interactions reflect future task operations. Nature Neuroscience. 2003; 6:75-81.

Sakai K, Passingham RE. Prefrontal set activity predicts rule-specific neural processing during subsequent cognitive performance. Journal of Neuroscience. 2006; 26:1211-1218. [PubMed: 16436608]

Salamone JD, Correa M. Motivational views of reinforcement: implications for understanding the behavioral functions of nucleus accumbens dopamine. Behavioural Brain Research. 2002; 137:325. [PubMed: 12445713]

Salamone JD, Correa M, Farrar A, Mingote SM. Effort-related functions of nucleus accumbens dopamine and associated forebrain circuits. Psychopharmacology. 2007; 191:461-482. [PubMed: 17225164]

Saxe R, Kanwisher N. People thinking about thinking people. The role of the temporo-parietal junction in "theory of mind". Neuroimage. 2003; 19(4):1835-1842. [PubMed: 12948738]

Schachter S, Singer JE. Cognitive, social, and physiological determinants of an emotional state. Psychological Review. 1962; 69:379-399. [PubMed: 14497895]

Schacter DL, Addis DR, Buckner RL. Remembering the past to imagine the future: the prospective brain. Nature Reviews. Neuroscience. 2007; 8(9):657-661.

Schmidt NB, Lerew DR, Trakowski JH. Body vigilance in panic disorder: Evaluating attention to bodily perturbations. Journal of Consulting and Clinical Psychology. 1997; 65:214-220. [PubMed: 9086684]

Seeley WW, Menon V, Schatzberg AF, Keller J, Glover GH, Kenna H, et al. Dissociable intrinsic connectivity networks for salience processing and executive control. Journal of Neuroscience. 2007; 27(9):2349-2349. [PubMed: 17329432] 
Sem-Jacobson, CW. Depth-electroencephalographic stimulation of the human brain and behavior. Thomas Publishing; Springfield, IL: Charles C: 1968.

Sifneos PE. The prevalence of 'alexithymic' characteristics in psychosomatic patients. Psychtherapy and Psychosomatics. 1973; 22:255-262.

Smith SM, Fox PT, Miller KL, Glahn DC, Fox PM, Mackay CE, et al. Correspondence of the brain's functional architecture during activation and rest. Proceedings of the Natlonal Academy of Science. 2009; 106(31):13040-13045.

Smith SM, Miller KA, Moeller S, Xu J, Auerbach EJ, Woolrich MW, et al. Temoprally-independent functional modes of spontaneous brain activity. Proceedings of the National Academy of Sciences. (in press).

Spreng RN, Grady CL. Patterns of brain activity supporting autobiographical memory, prospection, and theory of mind, and their relationship to the default mode network. Journal of Cognitive Neuroscience. 2010; 22(6):1112-1123. [PubMed: 19580387]

Spreng RN, Mar RA, Kim ASN. The common neural basis of autobiographical memory, prospection, navigation, theory of mind, and the default mode: a quantitative meta-analysis. Journal of Cognitive Neuroscience. 2009; 21(3):489-510. [PubMed: 18510452]

Stark CE, Squire LR. When zero is not zero: The problem of ambiguous baseline conditions in fMRI. Proceedings of the National Academy of Sciences. 2001; 98(22):12760-12766.

Touroutoglou A, Hollenbeck M, Dickerson BC, Barrett LF. Dissociable large-scale networks anchored in the anterior insula subserve affective experience and attention/executive function. NeuroImage. (in press).

Tsakiris M, Constantini M, Haggard P. The role of the right temporo-parietal junction in maintaining a coherent sense of one's body. Neuropsychologia. 2008; 46(3014-3018)

Uttal, WR. The new phrenology: The limits of localizing cognitive processes in the brain. The MIT Press; 2001.

Valenstein, ES. Brain control: a critical examination of brain stimulation and psychosurgery. John Wiley \& Sons; 1974.

Van der Horst VGJM, Holstege G. Sensory and motor components of reproductive behavior: pathways and plasticity. Behavioural Brain Research. 1998; 92(2):157-167. [PubMed: 9638958]

van der Kouwe AJ, Benner T, Salat DH, Fischl B. Brain morphometry with multiecho MPRAGE. Neuroimage. 2008; 40(2):559-569. [PubMed: 18242102]

Vataja R, Leppavuori A, Pohjasvaara T, Mantyla R, Aronen HJ, Salonen O, et al. Poststroke depression and lesion location revisited. Journal of Neuropsychiatry and Clinical Neuroscience. 2004; 16:156-162.

Vincent JL, Kahn I, Snyder AZ, Raichle ME, Buckner RL. Evidence for a frontoparietal control system revealed by intrinsic functional connectivity. Journal of Neurophysiology. 2008; 100(6): 3328-3342. [PubMed: 18799601]

Visser M, Jefferies E, Ralph M. A. Lambon. Semantic processing in the anterior temporal lobes: A meta-analysis of the functional neuroimaging literature. Journal of Cognitive Neuroscience. 2010; 22(6):1083-1094. [PubMed: 19583477]

Wager TD, Barrett LF. From affect to control: Functional specialization of the insula in motivation and regulation. PsycExtra. 2004 Retrieved from.

Wager, TD.; Barrett, LF.; Bliss-Moreau, E.; Lindquist, KA.; Duncan, S.; Kober, H.; Mize, J. The neuroimaging of emotion. In: Lewis, M.; Haviland-Jones, JM.; Barrett, LF., editors. Handbook of emotions. 2nd ed. Guilford; New York: 2008. p. 513-530.

Wager TD, Davidson ML, Hughes BL, Lindquist MA, Ochsner KN. Prefrontal-subcortical pathways mediating successful emotion regulation. Neuron. 2008; 59:1037-1050. [PubMed: 18817740]

Wager TD, Waugh CE, Lindquist M, Noll DC, Fredrickson BL, Taylor SF. Brain mediators of cardiovascular responses to social threat, Part I: Reciprocal dorsal and ventral sub-regions of the medial prefrontal cortex and heart-rate reactivity. NeuroImage. 2009; 47:821-35. [PubMed: 19465137]

Whalen PJ, Rauch SL, Etcoff NL, McInerney SC, Lee MB, Jenike MA. Masked presentations of emotional facial expressions modulate amygdala activity without explicit knowledge. Journal of Neuroscience. 1998; 18(1):411-411. [PubMed: 9412517] 
Wicker B, Keysers C, Plailly J, Royet JP, Gallese V, Rizzolatti G. Both of Us Disgusted in My Insula The Common Neural Basis of Seeing and Feeling Disgust. Neuron. 2003; 40(3):655-664. [PubMed: 14642287]

Wilson-Mendenhall CD, Barrett LF, Simmons WK, Barsalou L. Grounding emotion in situated conceptualization. Neuropsychologia. 2011; 49:1105-1127. [PubMed: 21192959]

Wundt, W. Outlines of psychology. Thoemmes Press; Bristol, UK: 1897/1998.

Yeo BT, Krienen FM, Sepulcre J, Sabuncu MR, Lashkari D, Hollinshead M, et al. The Organization of the Human Cerebral Cortex Estimated By Functional Connectivity. Journal of Neurophysiology. 2011; 106:1125-1165. [PubMed: 21653723]

Young L, Cushman F, Hauser M, Saxe R. The neural basis of the interaction between theory of mind and moral judgment. Proceedings of the National Academy of Sciences. 2007; 104(20):82358240 .

Young L, Scholz J, Saxe R. Neural evidence for "intuitive prosecution": The use of mental state information for negative moral verdicts. Social Cognition. (in press). 


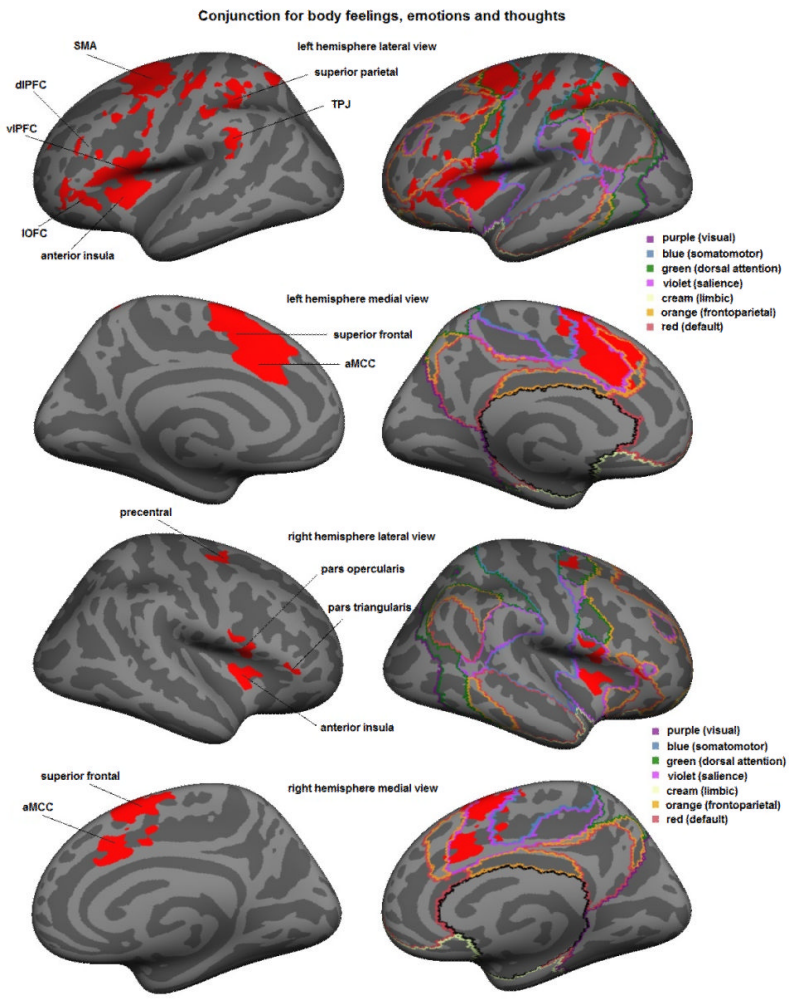

Figure 1.

Conjunction for experience phase across body feelings, emotions and thoughts. 


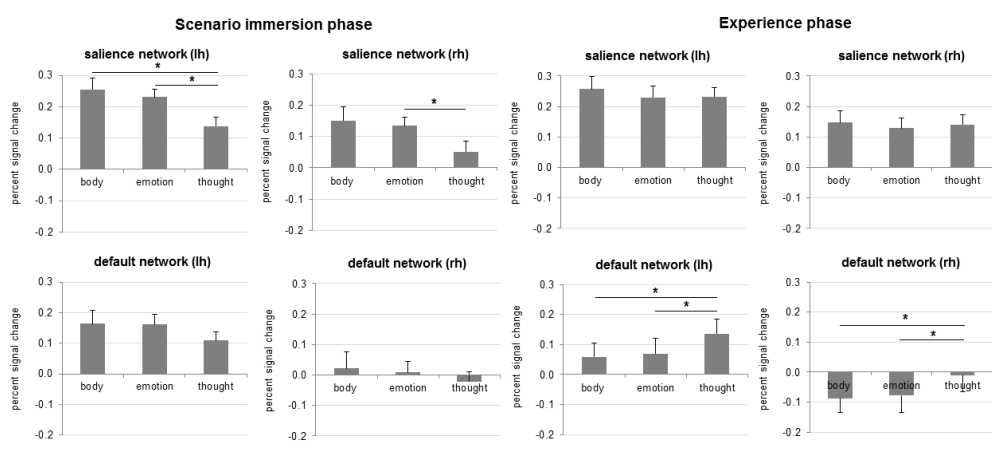

Figure 2.

Region of interest analyses demonstrating differential involvement of the default network and the salience network across different mental states for the scenario immersion and the experience phase. Graphs represent percent signal change, bars represent standard error. * p $<.05$ 


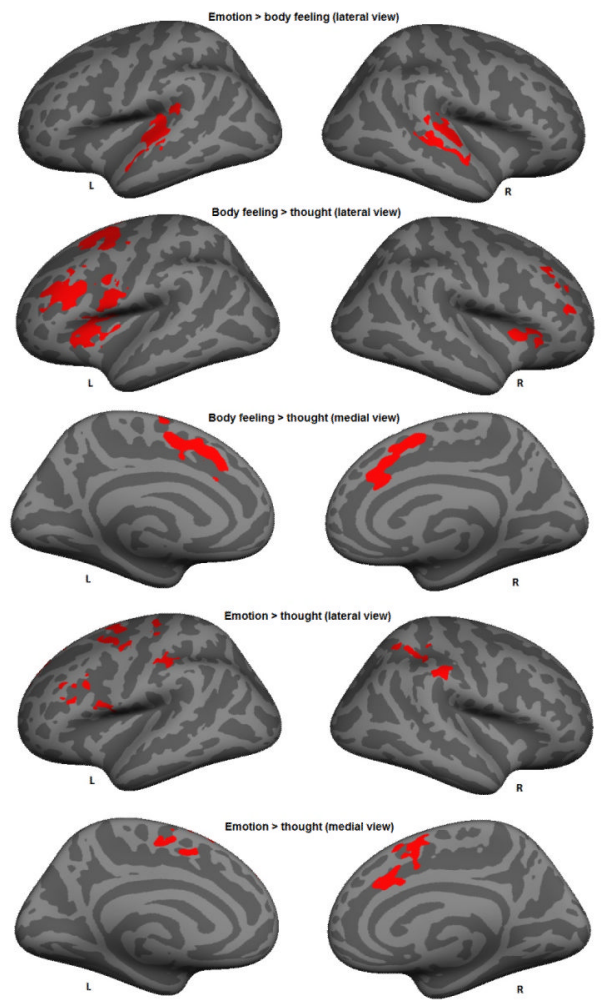

Figure 3.

Left and right hemispheres (lateral and medial view) with activation patterns for emotions > body feelings, body feelings $>$ thoughts and emotions $>$ thoughts for the scenario immersion phase. Clusters of vertices are significant at $p<.01$ corrected for multiple comparisons (Monte Carlo). 

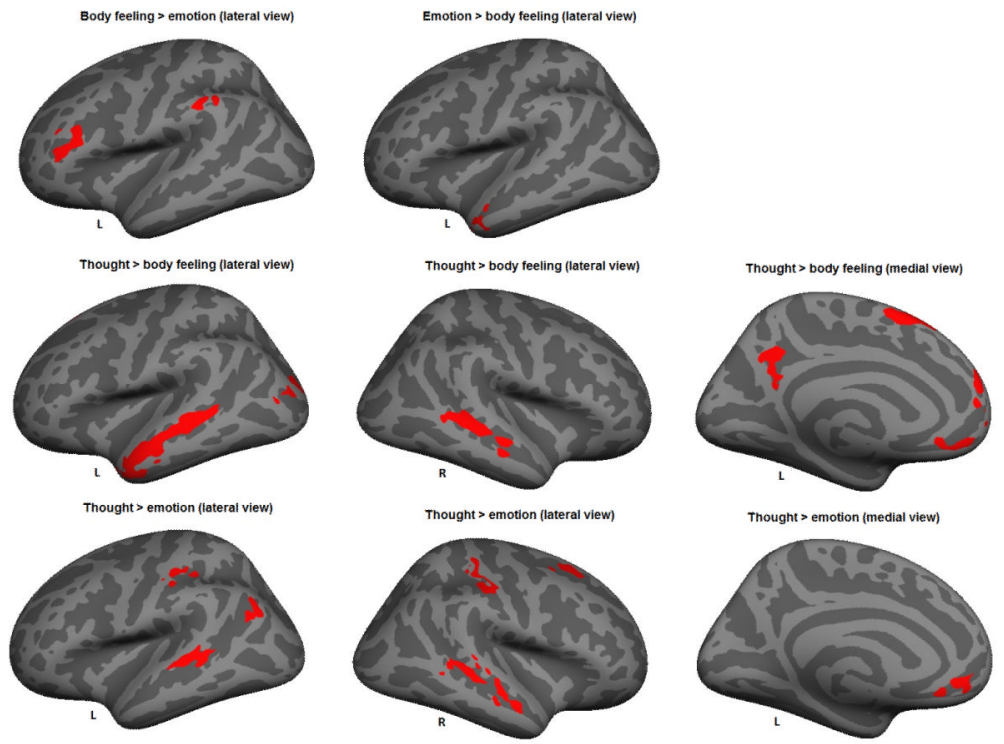

Figure 4.

Left hemispheres (lateral and medial view) with activation clusters for body feelings> emotions, emotions $>$ body feelings, thoughts $>$ body feelings and thoughts $>$ emotions for the experience phase. Clusters of vertices are significant at $p<.01$ corrected for multiple comparisons (Monte Carlo) 
Table 1

Overview of seven networks of interest

\begin{tabular}{|c|c|c|c|}
\hline Network & Brain regions & Task domains & $\begin{array}{l}\text { Psychological description } \\
\text { and hypotheses }\end{array}$ \\
\hline $\begin{array}{l}\text { "limbic network" (Yeo } \\
\text { et al., 2011) }\end{array}$ & $\begin{array}{l}\text { bilateral anterior temporal } \\
\text { lobe, } \\
\text { medial temporal lobe, } \\
\text { subgenual } \\
\text { anterior cingulate cortex, } \\
\text { medial } \\
\text { and lateral orbitofrontal } \\
\text { cortex } \\
\text { (although Yeo et al.'s } \\
\text { network } \\
\text { only covers the cortex, we } \\
\text { also } \\
\text { hypothesize that the basal } \\
\text { ganglia } \\
\text { including the caudate, } \\
\text { putamen, } \\
\text { globuspallidus and central } \\
\text { nucleus } \\
\text { of the amygdala will be a part } \\
\text { of } \\
\text { this network). }\end{array}$ & $\begin{array}{l}\text { - } \quad \text { emotion and affect (Lindquist et al., in } \\
\text { press; Andrews-Hanna et al., 2010) } \\
\text { autobiographical memory (Spreng\& } \\
\text { Grady, 2010) }\end{array}$ & $\begin{array}{l}\text { core affect generation: } \\
\text { engaging visceromotor } \\
\text { control of the body to create } \\
\text { core affective feelings } \\
\text { of pleasure or displeasure } \\
\text { with some degree of } \\
\text { arousal. } \\
\text { Hypothesis: Body feeling } \\
\text { and Emotion > Thought }\end{array}$ \\
\hline $\begin{array}{l}\text { "salience network" } \\
\text { (Seeley et al., 2007) or } \\
\text { "ventral attention } \\
\text { network" (Yeo et al., } \\
\text { 2011; Corbetta\& } \\
\text { Shulman, 2002) or } \\
\text { "cingulo-opercular } \\
\text { network"(Vincent et } \\
\text { al., 2008) }\end{array}$ & $\begin{array}{l}\text { bilateral anterior } \\
\text { midcingulate } \\
\text { cortex (aMCC), anterior } \\
\text { insula } \\
\text { (AI) and mid-insula, frontal } \\
\text { operculum, and parts of the } \\
\text { pars } \\
\text { opercularis and } \\
\text { temporoparietal } \\
\text { junction }\end{array}$ & $\begin{array}{l}\text { cognitive control(Cole \& Schneider, } \\
\text { 2007) } \\
\text { - } \quad \text { stimulus-driven control of attention } \\
\text { (Corbetta\& Shulman, 2002) } \\
\text { - } \quad \text { set maintenance (Dosenbach et al., } \\
2006 \text { ) } \\
\text { maintaining sub-goals (Fincham et al., } \\
\text { - } 2002 \text { ) } \\
\text { anxiety (Seeley et al., 2007) } \\
\text { representation of the body (Craig, } \\
\text { 2009) } \\
\text { pain (Lamm et al., 2010) }\end{array}$ & $\begin{array}{l}\text { body-directed attention: } \\
\text { using representations from } \\
\text { the body to guide attention } \\
\text { and behavior. This } \\
\text { ingredient might use } \\
\text { changes in the homeostatic } \\
\text { state } \\
\text { of the body to signal salient } \\
\text { events in the } \\
\text { environment and regulate } \\
\text { behavioral responses. } \\
\text { Hypothesis: Body } \\
\text { feelingand Emotion > } \\
\text { Thought }\end{array}$ \\
\hline $\begin{array}{l}\text { "default network" } \\
\text { (Dosenbach et al., } \\
\text { 2008; } \\
\text { Vincent et al., 2008; } \\
\text { Yeo et al., 2011) }\end{array}$ & $\begin{array}{l}\text { medial prefrontal cortex, } \\
\text { parts of } \\
\text { the pars triangularis, } \\
\text { retrosplenial } \\
\text { area, posterior cingulate } \\
\text { cortex/precuneus, medial } \\
\text { temporal lobe (hippocampus, } \\
\text { entorhinal cortex), bilateral } \\
\text { superior temporal sulcus, } \\
\text { parts of } \\
\text { the anterior temporal lobe } \\
\text { (ATL), } \\
\text { and angular gyrus }\end{array}$ & $\begin{array}{ll}\text { - } & \text { autobiographical memory(Spreng\& } \\
\text { Grady, 2010) } \\
\text { - } & \text { prospection(Spreng\& Grady, 2010) } \\
\text { - } & \text { theory of mind(Spreng\& Grady, 2010) } \\
\text { - } & \text { moral reasoning (Greene at al., 2001) } \\
\text { - } & \text { context-sensitive visual perception } \\
\text { (Bar, 2004) } \\
\text { - } \quad \text { spontaneous thought (Andrews-Hanna } \\
\text { et al., 2010) } \\
\text { emotion (Lindquist et al., in press; } \\
\text { Andrews-Hanna et al., 2010) } \\
\text { - } \quad \begin{array}{l}\text { semantics, phonology, sentence } \\
\text { processing (Binder et al. 2009) }\end{array}\end{array}$ & $\begin{array}{l}\text { conceptualization: } \\
\text { representing prior } \\
\text { experiences } \\
\text { (i.e., memory or category } \\
\text { knowledge) to make } \\
\text { meaning of sensations from } \\
\text { the body and the world } \\
\text { in the moment. } \\
\text { Hypothesis: Thought and } \\
\text { Emotion > Body feeling }\end{array}$ \\
\hline $\begin{array}{l}\text { "frontoparietal } \\
\text { network" } \\
\text { (Dosenbach et al., } \\
\text { 2008; }\end{array}$ & $\begin{array}{l}\text { bilateral dorsolateral } \\
\text { prefrontal } \\
\text { cortex (dlPFC), inferior } \\
\text { parietal }\end{array}$ & $\begin{array}{l}\text { - } \quad \text { task-switching (Crone et al., 2006) } \\
\text { alerting to a stimulus after a cue (Fan } \\
\text { et al., 2005) } \\
\text { - } \quad \text { planning (Fincham et al., 2002) }\end{array}$ & $\begin{array}{l}\text { executive attention: } \\
\text { modulating activity in other } \\
\text { ingredients to create a } \\
\text { unified conscious field } \\
\text { during }\end{array}$ \\
\hline
\end{tabular}




\begin{tabular}{|c|c|c|c|}
\hline Network & Brain regions & Task domains & $\begin{array}{l}\text { Psychological description } \\
\text { and hypotheses }\end{array}$ \\
\hline $\begin{array}{l}\text { Vincent et al., 2008; } \\
\text { Yeo et al., 2011) or } \\
\text { "executive } \\
\text { control network" } \\
\text { (Seeley et al., 2007) }\end{array}$ & $\begin{array}{l}\text { lobe, inferior parietal sulcus, } \\
\text { and } \\
\text { aspects of the middle } \\
\text { cingulate } \\
\text { cortex (mCC) }\end{array}$ & $\begin{array}{ll}\cdot & \text { rule-specific processing (Sakai } \\
& \& \text { Passingham, 2006) } \\
& \text { working memory (Sakai } \\
& \& \text { Passingham, 2003) }\end{array}$ & $\begin{array}{l}\text { the construction of a mental } \\
\text { state (e.g., selecting } \\
\text { some conceptual content } \\
\text { when meaning is made of } \\
\text { sensations and inhibiting } \\
\text { other content; selecting } \\
\text { some sensations for } \\
\text { conscious awareness and } \\
\text { inhibiting others). } \\
\text { No specific hypothesis } \\
\text { formulated }\end{array}$ \\
\hline $\begin{array}{l}\text { "dorsal attention } \\
\text { network" (Corbetta\& } \\
\text { Shulman, 2002; Yeo et } \\
\text { al., 2011;) }\end{array}$ & $\begin{array}{l}\text { bilateral frontal eye fields, } \\
\text { dorsal } \\
\text { posterior parietal cortex, } \\
\text { fusiform } \\
\text { gyrus, area MT+ }\end{array}$ & $\begin{array}{l}\text { - top-down control of visuospatial attention } \\
\text { (Corbetta et al., 2002) }\end{array}$ & $\begin{array}{l}\text { visuospatial attention: } \\
\text { modulating activity in an } \\
\text { ingredient for processing } \\
\text { visual content in particular } \\
\text { (e.g., selecting which visual } \\
\text { sensation is selected for } \\
\text { conscious awareness and } \\
\text { inhibiting others). } \\
\text { No specific hypothesis } \\
\text { formulated }\end{array}$ \\
\hline $\begin{array}{l}\text { "somatomotor } \\
\text { network" } \\
\text { (Yeo et al. 2011) }\end{array}$ & $\begin{array}{l}\text { precentral and postcentralgyri } \\
\text { (sensorimotor cortex), } \\
\text { Heschl'sgyrus (primary } \\
\text { auditory } \\
\text { cortex) cortex, posterior } \\
\text { insula }\end{array}$ & $\begin{array}{l}\text { - } \quad \text { audition (Morosan et al. 2001) } \\
\text { somatovisceral sensation (Eickhoff et } \\
\text { al. 2006) }\end{array}$ & $\begin{array}{l}\text { exteroceptive sensory } \\
\text { perception: representing } \\
\text { auditory and tactile } \\
\text { sensations } \\
\text { No specific hypothesis } \\
\text { formulated }\end{array}$ \\
\hline $\begin{array}{l}\text { "visual network" (Yeo } \\
\text { et al. 2011) }\end{array}$ & occipital lobe & - vision (Engel et al. 1994) & $\begin{array}{l}\text { exteroceptive sensory } \\
\text { perception: representing } \\
\text { visual sensations } \\
\text { No specific hypothesis } \\
\text { formulated }\end{array}$ \\
\hline
\end{tabular}

Note: The table lists the brain regions that are found to comprise each network across studies (column 1), the references that contribute to a functional understanding of each network (column 2) and the psychological description that is supported by the network as hypothesized by a constructionist framework (see further Lindquist \& Barrett, under review). 


\section{Table 2}

Two examples of the full and condensed versions of the negative scenarios used in the experiment (based on Wilson-Mendenhall et al., 2011).

\begin{tabular}{ll}
\hline Full Version & Full Version \\
$\begin{array}{l}\text { You're driving home after staying out drinking all } \\
\text { night. The long stretch of road in front of you } \\
\text { seems to go on forever. You close your eyes for a } \\
\text { moment. The car begins to skid. You jerk awake. } \\
\text { You feel the steering wheel slip in your hands. }\end{array}$ & $\begin{array}{l}\text { Everywhere you look, people are picnicking and } \\
\text { playing. The front tire hits a pot hole. You sail } \\
\text { over the handlebars. Your head slams into the } \\
\text { concrete surface. You can feel blood trickling } \\
\text { down your face. }\end{array}$ \\
$\begin{array}{ll}\text { Condensed Version } \\
\begin{array}{l}\text { You're driving home after staying out drinking all } \\
\text { night. You close your eyes for a moment, and the } \\
\text { car begins to skid. }\end{array}\end{array}$ & $\begin{array}{l}\text { You're biking through a park without a helmet. } \\
\text { Your front tire hits a pot hole, and you sail over the } \\
\text { handlebars. }\end{array}$ \\
\hline
\end{tabular}




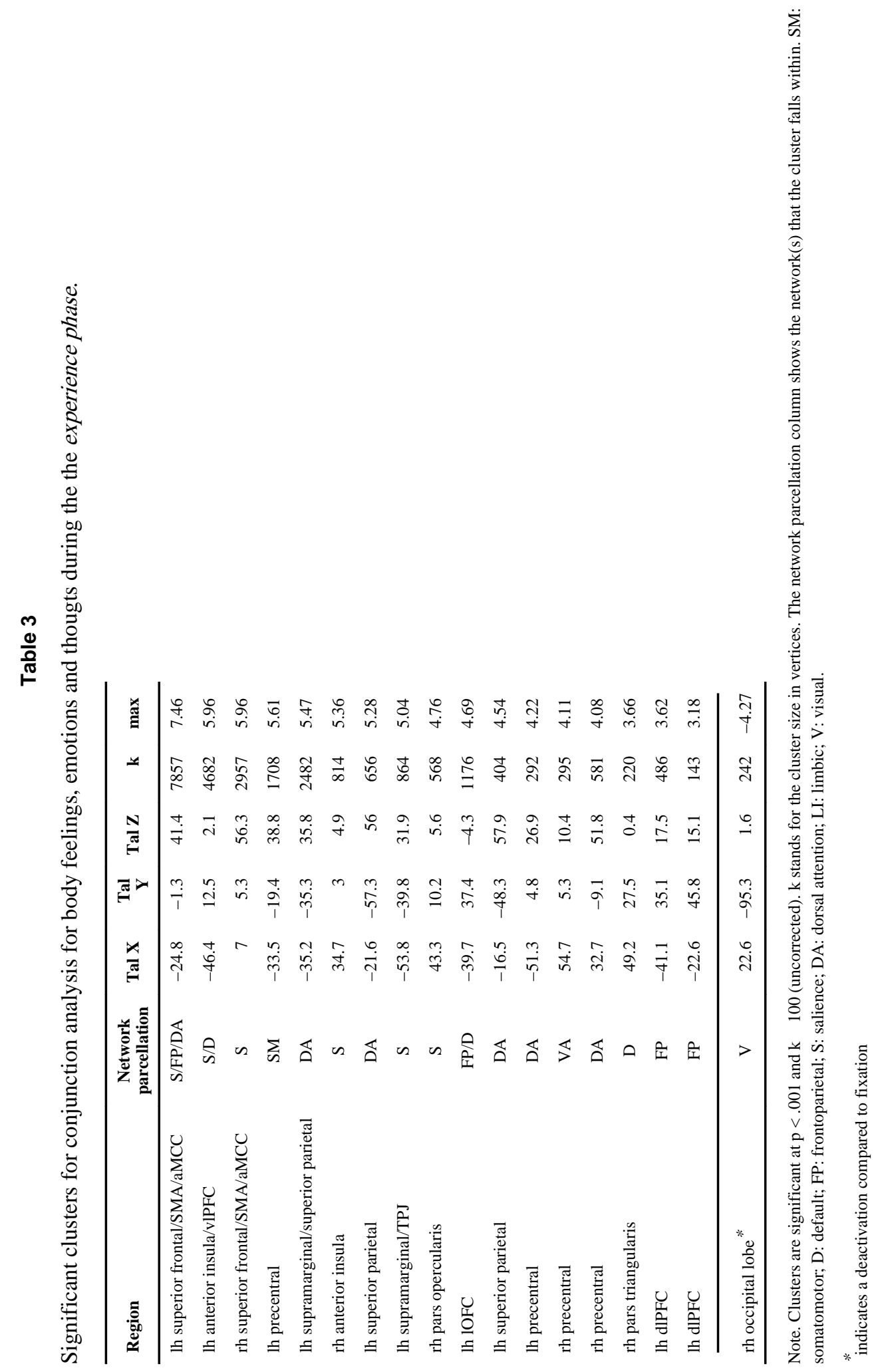






Page 40 


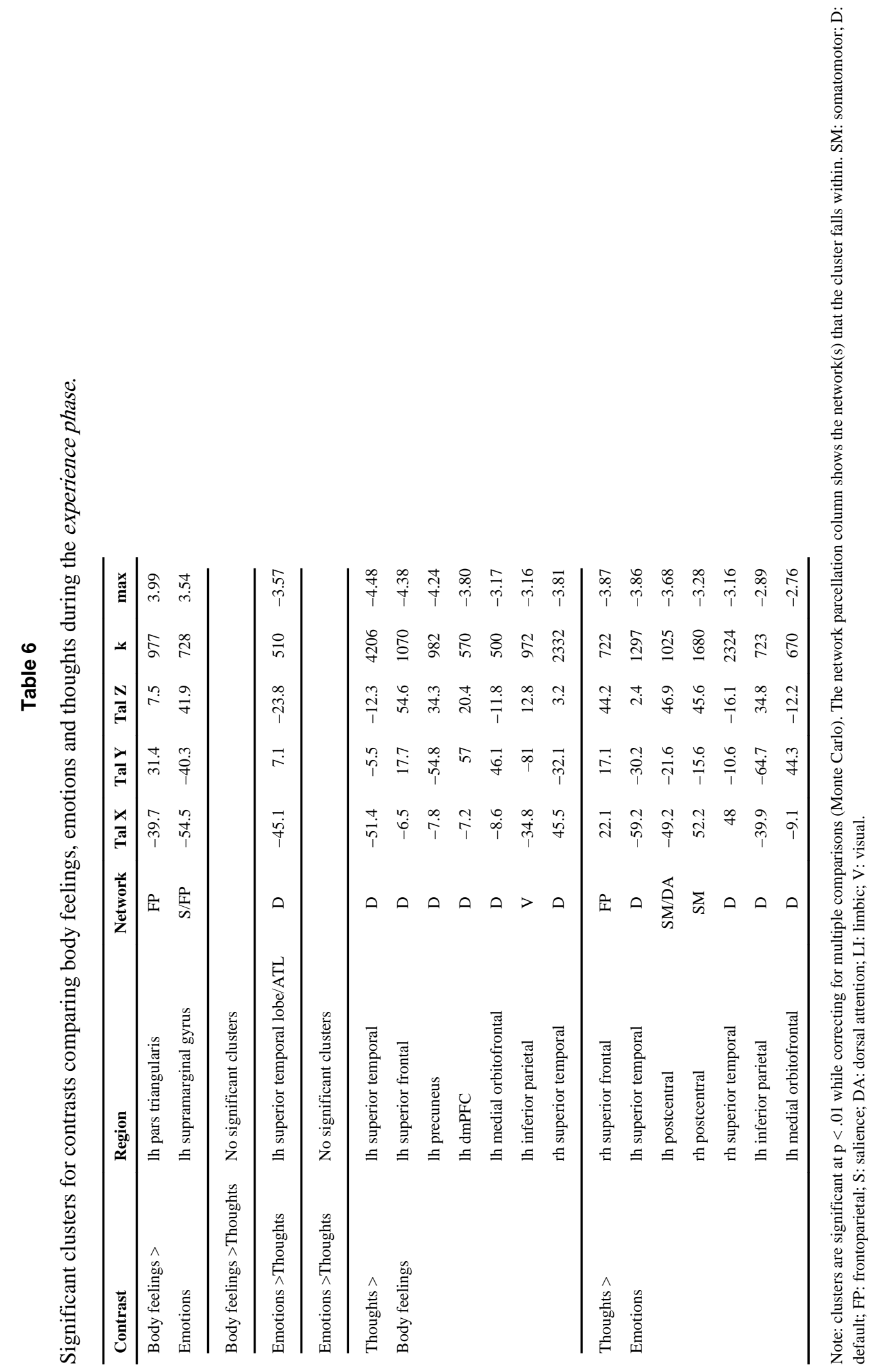


Table 7

Summary of findings

\begin{tabular}{ll}
\hline Hypothesis & Analysis showing support \\
\hline $\begin{array}{l}\text { 1: Common networks involved in } \\
\text { emotions, body feelings, \& } \\
\text { thoughts }\end{array}$ & $\begin{array}{l}\text { Conjunction: involvement of salience network, default network and frontoparietal } \\
\text { network across emotion, body and thought }\end{array}$ \\
\hline $\begin{array}{l}\text { 2: Relative differences in network } \\
\text { involvement across emotion, body, } \\
\& \text { thought }\end{array}$ & \\
\hline $\begin{array}{l}\text { 2a: Body \& emotion }>\text { thought for } \\
\text { limbic network and salience } \\
\text { network }\end{array}$ & $\begin{array}{l}\text { ROI: body }=\text { emotion }>\text { thought for salience network in scenario immersion phase } \\
\text { Contrast: body }>\text { thoughts for salience network during scenario immersion }\end{array}$ \\
\hline $\begin{array}{l}\text { Contrast: emotion }>\text { thoughts for salience network during scenario immersion } \\
\text { Contrast: body }>\text { thoughts for limbic during scenario immersion }\end{array}$ \\
$\begin{array}{ll}\text { default network } & \begin{array}{l}\text { ROI: thought }>\text { emotion }=\text { body for default network in experience phase } \\
\text { Contrast: thoughts }>\text { body in default network during experience phase }\end{array} \\
\text { Contrast: thoughts }>\text { emotion in default network during experience phase }\end{array}$ \\
\begin{tabular}{ll} 
Contrast: emotion $>$ body in default network during experience phase \\
\hline
\end{tabular}
\end{tabular}

